\title{
Multiple observation types reduce uncertainty in Australia's terrestrial carbon and water cycles
}

\author{
V. Haverd ${ }^{1}$, M. R. Raupach ${ }^{1}$, P. R. Briggs ${ }^{1}$, J. G. Canadell ${ }^{1}$, P. Isaac ${ }^{1}$, C. Pickett-Heaps ${ }^{1}$, S. H. Roxburgh ${ }^{2}$, \\ E. van Gorsel ${ }^{1}$, R. A. Viscarra Rossel $^{3}$, and Z. Wang ${ }^{1,4}$ \\ ${ }^{1}$ CSIRO Marine and Atmospheric Research, P.O. Box 3023, Canberra ACT 2601, Australia \\ ${ }^{2}$ CSIRO Ecosystem Sciences, P.O. Box 1700, Canberra ACT 2601, Australia \\ ${ }^{3}$ CSIRO Land and Water, P.O. Box 1666, Canberra ACT 2600, Australia \\ ${ }^{4}$ IBM Research-Australia, 204 Lygon St., Carlton, VIC 3053, Australia
}

Correspondence to: V. Haverd (vanessa.haverd@csiro.au)

Received: 26 July 2012 - Published in Biogeosciences Discuss.: 11 September 2012

Revised: 10 January 2013 - Accepted: 13 February 2013 - Published: 25 March 2013

\begin{abstract}
Information about the carbon cycle potentially constrains the water cycle, and vice versa. This paper explores the utility of multiple observation sets to constrain a land surface model of Australian terrestrial carbon and water cycles, and the resulting mean carbon pools and fluxes, as well as their temporal and spatial variability. Observations include streamflow from 416 gauged catchments, measurements of evapotranspiration (ET) and net ecosystem production (NEP) from 12 eddy-flux sites, litterfall data, and data on carbon pools. By projecting residuals between observations and corresponding predictions onto uncertainty in model predictions at the continental scale, we find that eddy flux measurements provide a significantly tighter constraint on continental net primary production (NPP) than the other data types. Nonetheless, simultaneous constraint by multiple data types is important for mitigating bias from any single type.

Four significant results emerging from the multiplyconstrained model are that, for the 1990-2011 period: (i) on the Australian continent, a predominantly semi-arid region, over half the water loss through ET $(0.64 \pm 0.05)$ occurs through soil evaporation and bypasses plants entirely; (ii) mean Australian NPP is quantified at $2.2 \pm 0.4$

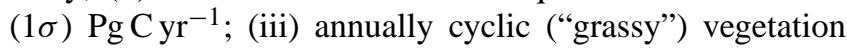
and persistent ("woody") vegetation account for $0.67 \pm 0.14$ and $0.33 \pm 0.14$, respectively, of NPP across Australia; (iv) the average interannual variability of Australia's NEP $\left( \pm 0.18 \mathrm{Pg} \mathrm{C} \mathrm{yr}^{-1}, 1 \sigma\right)$ is larger than Australia's total anthropogenic greenhouse gas emissions in 2011 (0.149 Pg C equivalent $\mathrm{yr}^{-1}$ ), and is dominated by variability in desert and savanna regions.
\end{abstract}

\section{Introduction}

Australian continental net primary productivity (NPP), and hence the Australian biospheric carbon cycle, is highly uncertain. In a review of twelve regional model estimates, Roxburgh et al. (2004) found a five fold variation of long-term annual Australian NPP, from 0.67 to $3.31 \mathrm{Pg} \mathrm{Cyr}^{-1}$, and a similar range across six dynamic global vegetation models. In another study, Wang and Barrett (2003) obtained annual mean NPP ranging from $0.8-1.1 \mathrm{Pg} \mathrm{C} \mathrm{yr}^{-1}$ during the 1990 1998 period, with uncertainty estimates of $20-30 \%$. More recent estimates of Australian NPP (1990-2010) from global ecosystem models participating in the carbon cycle model intercomparison project (TRENDY) (Sitch and Friedlingstein, 2011) are also highly variable $\left(2.2 \mathrm{PgC} \mathrm{yr}^{-1}\right.$ (range) and $\left.0.8 \mathrm{Pg} \mathrm{C} \mathrm{yr}^{-1}(1 \sigma)\right)$.

It is likely that the large uncertainty in the Australian biospheric carbon cycle can be reduced by a multiple constraints approach (e.g. Raupach et al., 2005) using information from both the carbon and water cycles. For example, we expect evapotranspiration (ET) and long-term streamflow (precipitation - ET) observations to be constraints on gross primary production (GPP) (and hence NPP), and information about GPP and NPP to provide significant constraints on the partitioning of ET into transpiration and soil evaporation. To test this, we use the CABLE land surface model (Wang et al., 2011) to evaluate continental NPP and soil evaporation as a fraction of ET (along with other key terms in the coupled carbon/water cycles, such as soil evaporation) and their uncertainties, constrained by (i) leaf NPP 
estimated from litterfall data; (ii) eddy covariance measurements of evapotranspiration (ET) and carbon dioxide $\left(\mathrm{CO}_{2}\right)$ fluxes, and (iii) long-term ET derived from streamflow. Further, the constrained NPP estimates are used to drive a carbon cycle model (CASA-CNP) to estimate biospheric carbon pools and turnover times and their uncertainties, constrained by carbon pool observations.

The paper is structured as follows. In Sect. 2, we describe the model, forcing data, observations for model constraint and evaluation and the model-data-fusion method. We then explore the value of using multiple constraints on model parameters and hence continental NPP (Sect. 3). In Sect. 4, we evaluate model predictions against observations. In Sect. 5 we present estimates of the mean continental carbon and water balances, and their uncertainties, assess the robustness of the uncertainty estimates and compare predictions with previous results. Finally, in Sect. 6 we quantify interannual variability in key components of the coupled carbon and water budgets.

\section{Methods and data sets}

\subsection{Land surface model description}

Coupled carbon and water cycles were simulated using a modified version of the CABLE land surface scheme in the BIOS2 modelling environment, a fine spatial resolution $\left(0.05^{\circ}\right)$ offline environment built on capability developed for the Australian Water Availability Project (King et al., 2009; Raupach et al., 2009). Hereafter we refer to the composite model and environment as BIOS2. BIOS2 includes: (1) a modification of the CABLE land surface scheme (Kowalczyk et al., 2006; Wang et al., 2011) as described below; (2) infrastructure for the treatment of inputs (gridded vegetation cover, meteorological data and parameters) and outputs for optimum efficiency; (3) a weather generator for downscaling of meteorological data; and (4) model-data fusion capability.

CABLE consists of five components (Wang et al., 2011): (1) the radiation module describes radiation transfer and absorption by sunlit and shaded leaves; (2) the canopy micrometeorology module describes the surface roughness length, zero-plane displacement height, and aerodynamic conductance from the reference height to the air within canopy or to the soil surface; (3) the canopy module includes the coupled energy balance, transpiration, stomatal conductance and photosynthesis of sunlit and shaded leaves; (4) the soil module describes heat and water fluxes within soil and snow at their respective surfaces; and (5) the ecosystem carbon module accounts for the respiration of stem, root and soil organic carbon decomposition. In BIOS2, the default CABLE v1.4 soil and carbon modules were replaced respectively by the SLI soil model (Haverd and Cuntz, 2010) and the CASACNP biogeochemical model (Wang et al., 2010).
Modifications to CABLE, SLI and CASA-CNP for use in BIOS2 are detailed in the Appendices. Changes to SLI relative to its original version include modified soil water extraction (Appendix A1), modified soil surface energy balance computation (Appendix A2), modified soil boundary layer resistance formulation (Appendix A3) and a new solution for the coupled heat and moisture equations under freezing conditions (Appendix A4). Of the CASA-CNP model, only the carbon-cycle equations were used, with the nitrogen and phosphorous cycles disabled. Additional CASA-CNP modifications, made to improve model performance against observations in this application, included using static allocation coefficients (rather than allocation coefficients dependent upon phenology, temperature, and soil moisture), and holding the ratio of NPP to GPP constant in time, instead of using the default growth respiration/maintenance respiration paradigm which is known to be problematic. Thornley (2011) reviews the use this paradigm and summarises that it fails largely because "There is no straightforward way of dealing with growth and maintenance separately because the pools and anabolic processes are the same for both growth and maintenance." Details of parameter sets for CABLE, SLI and CASA-CNP are given in Appendix B. The combined CABLE and SLI models are referred to as CABLE-SLI throughout this paper.

CABLE was run at an hourly time step for the 1960-2011 period, with the first ten-years being used to initialise soil moisture. Atmospheric $\mathrm{CO}_{2}$ concentration was prescribed using actual deseasonalised values from global in situ observations (Keeling et al., 2001). Resulting daily aggregates of gross primary productivity (GPP), soil moisture and soil temperature were used to force CASA-CNP at daily time steps. CASA-CNP carbon pools were initialised by spinning the model 200 times for the 1970-1989 period using CABLE output for this period. The simulation period was 1990-2011, for which monthly outputs at $0.05^{\circ}(\sim 5 \mathrm{~km})$ spatial resolution were produced.

\subsection{Forcing data}

BIOS2 is forced using gridded meteorological data, soil properties and vegetation cover at $0.05^{\circ}$ spatial resolution, which are described briefly below. Further details of the meteorological data and soil properties appear in Appendix B.

Meteorology: The meteorological data comprise daily gridded rainfall, temperature, vapour pressure and solar irradiance surfaces from the Bureau of Meteorology's Australian Water Availability Project data set (BoM AWAP) (Grant et al., 2008; Jones et al., 2009). Data are downscaled from daily to hourly time steps (on the half-hour) using a weather generator within BIOS2.

Soil: Soil information is taken from the McKenzie and Hook (1992) and McKenzie et al. (2000) interpretations of the 725 principal profile forms (soil types) mapped in the 
Digital Atlas of Australian Soils (Northcote et al., 1960, 1975).

Vegetation Cover: Each grid cell is partitioned into woody and grassy tiles, and each tile is assigned a leaf area index (LAI), which is used to drive CABLE. The LAI of the grassy tile is partitioned into $\mathrm{C}_{3} / \mathrm{C}_{4}$ components.

LAI is derived from $f P A R$ (fraction photosynthetic absorbed radiation) estimates obtained from the AVHRR (1990-2006) (Donohue et al., 2009) and MODIS (20002011) time series. Total $f P A R$ is partitioned into persistent (mainly woody) and recurrent (mainly grassy) vegetation components, following the methodology of Donohue et al. (2009) and Lu et al. (2003). This methodology takes advantage of low levels of seasonal change in LAI in woody vegetation, allowing seasonal variation in $P P A R$ to be attributed principally to grassy vegetation. The remaining and relatively constant $P P A R$ signal is attributed to woody vegetation. LAI for woody and grassy components are estimated by Beer's Law (e.g. Houldcroft et al., 2009):

$\mathrm{LAI}_{\mathrm{V}}=-\frac{1}{k} \log _{e}\left(1-f P A R_{\mathrm{V}}\right)$

where $\mathrm{V}$ denotes the vegetation type (either $\mathrm{W}$ : persistent or mainly woody or G: recurrent or mainly grassy) and $k$ is an extinction coefficient, set here to 0.5 .

Fractional woody and grassy tile areas are given by $f P A R_{\mathrm{W}}$ and $\left(1-f P A R_{\mathrm{W}}\right)$, respectively. LAI in each tile was normalised by the fractional tile area, and each flux computed for each tile was scaled by fractional tile area to give persistent and recurrent flux components for each grid cell.

Grassy LAI was partitioned between $\mathrm{C}_{3}$ and $\mathrm{C}_{4}$ components according to the proportion of all grass species that are $\mathrm{C}_{4}$ species, as estimated by Hattersley (1983). The proportion is estimated as a function of average minimum temperature in January and the average August precipitation. The $\mathrm{C}_{3} / \mathrm{C}_{4}$ grass distribution is similar to other published distribution maps for Australia (Murphy and Bowman, 2007), showing a predominance of $\mathrm{C}_{4}$ grasses in northern and central Australia and a predominance of $\mathrm{C}_{3}$ grasses in southern Australia. A relatively narrow latitude band centred at $\sim 30^{\circ}$ exists where there is approximately equal relative distributions in $\mathrm{C}_{3}$ and $\mathrm{C}_{4}$ grasses.

MODIS-derived and AVHRR-derived vegetation cover were used to force BIOS2 in separate simulations, with an annual climatology being used outside of the period of data availability. Parameter estimation was performed separately prior to each simulation. Most of the results presented in Sections 3-6 are derived using AVHRR (which covers a longer period). Exceptions are the simulations for the flux tower sites (Sect. 4.1), for which we use MODIS because it spans the observation periods of the flux data, and the continental time series (Sect. 6), for which we present both simulations.

\subsection{Regionalisation of results}

For the purpose of examining model output at regional scale, we use a simple aggregation of classes from the agro-climatic classification of Hutchinson et al. (2005, Table 2, Fig. 3), which itself is a digital reanalysis for Australia of the global scheme of Hutchinson et al. (1992). The scheme is quite similar to that of Köppen (1923) and its variants, but with a stronger relation to the dynamics of plant growth (Hutchinson et al., 2005). The original 18-class Hutchinson data grid at $0.025^{\circ}$ resolution was aggregated to $0.05^{\circ}$ (by dominant class) with minimal loss of spatial structure. The 18 original classes were then collapsed into 6 classes: tropics, savanna, warm temperate, cool temperate, Mediterranean, and desert. The result (Fig. 1) is a classification of the continent into mostly-contiguous regions that are internally similar in climate and biophysical characteristics.

\subsection{Data sets for parameter estimation and model evaluation}

We used several types of observations for parameter estimation (Sect. 2.5 below) and model evaluation. Locations of observations are shown in Fig. 2. For each data type, less than $30 \%$ of the data was used in parameter estimation, except for eddy flux data, of which we used 6 out of 12 sites for parameter estimation. All data sets were used in their entirety for model evaluation.

\subsubsection{Streamflow data}

Quality controlled daily streamflow records for 416 unregulated catchments were obtained from the datasets of Vaze et al. (2011) (231 of 232 for south-eastern Australia), and Zhang et al. (2011) (185 of 719 Australia-wide). Streamflow records for these catchments were intermittent during the period 1950-2010. For each catchment, monthly streamflow values were obtained by averaging daily data for months with at least $90 \%$ of days observed, and set to missing values otherwise. Mean long-term evapotranspiration was calculated from (precipitation - streamflow), ignoring months with missing streamflow data, for comparison with mean modelled evaporation for the corresponding periods. In doing so, we assume the change in stored water over the averaging period is negligible compared to the cumulative evaporation flux. The above filtering reduced the number of catchments for model evaluation to 362, of which 50 (10 from each bioclimatic region except desert) were randomly selected for parameter estimation.

\subsubsection{Eddy flux sata}

Table 1 lists the 12 OzFlux sites used for parameter estimation and model evaluation, and summarises site characteristics and time periods corresponding to the data used. Measures of ET and GPP from 6 sites were used in the 


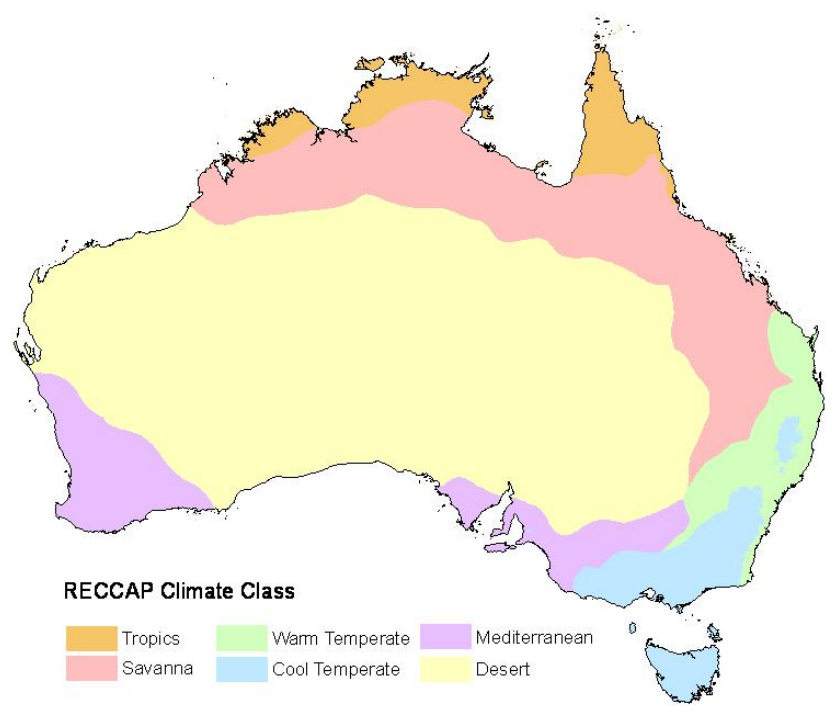

Fig. 1. Bioclimatic classification for use in regionalisation of results.

parameter estimation, and measures of ET, GPP, NEP and total water use efficiency (WUE) from all 12 sites were included in model evaluation. Sites used for parameter estimation are indicated in Table 1 by the presence of a parameter estimation time period (last column). We used non-gapfilled, quality-controlled data, which had been processed according to Aubinet et al. (2000). No correction for energy closure was applied, because energy closure is generally good across the Ozflux sites. Frequency distributions for the slope (forced through zero) of the sum of daily averaged sensible and latent heat fluxes versus available energy peak at 1.00 (full width at half maximum of 0.24) for the OzFlux dataset (Leuning et al., 2012).

Gaps in the data were reproduced in the model predictions prior to aggregation to ensure temporal compatibility between observations and predictions. These fluxes were used only for parameter estimation and model evaluation, not for forming site carbon and water budgets, so the presence of gaps is not critical.

Since GPP is not measured directly, we construct a closely related variable $\mathrm{GPP}^{\prime}$ from the observable NEP: $\mathrm{GPP}_{t}^{\prime}=\mathrm{NEP}_{t}-\mathrm{NEP}_{00: 00}$, where subscripts $t$ and 00:00 denote time of day and midnight, respectively. In other words, GPP' is GPP plus the difference between daytime and nighttime ecosystem respiration on a daily basis. The latter difference is expected to be small (van Gorsel et al., 2009).

The mean flux (ET, GPP' or NEP anomaly) for each month (year) of the observation record was estimated by integrating the mean diurnal cycle of the flux for each month (year). Absolute values of NEP were not used for model evaluation because there is as yet no explicit account of disturbance in BIOS2, resulting in limited predictability of mean source or sink strength. NEP anomaly was calculated by subtracting

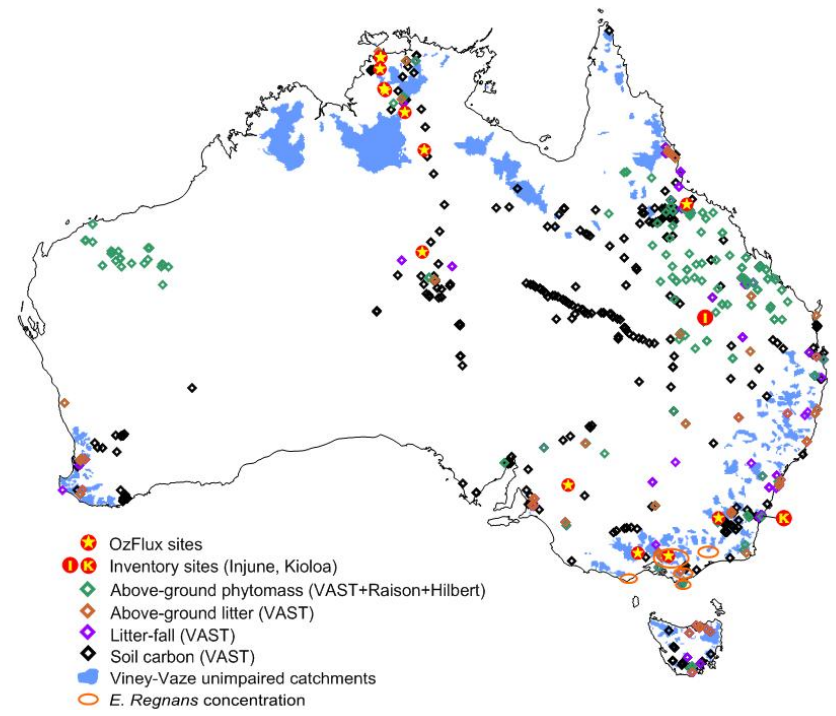

Fig. 2. Location of observations.

the mean monthly (or annual) NEP over the period of observation. BIOS2 was also evaluated against monthly (or annual) total water use efficiency (WUE), defined here as the ratio of GPP' to ET at monthly (or annual) time scale.

The Howard Springs OzFlux site is also one of three similar study sites used to estimate the carbon balance of a tropical savanna (Chen et al., 2003). In this study the carbon balance was constructed from estimates of above- and belowground biomass, annual biomass increment, fine root production and turnover, litterfall, canopy respiration and total soil $\mathrm{CO}_{2}$ efflux. We compare BIOS2 estimates of carbon fluxes and stores at Howard Springs with estimates from this study.

\subsubsection{Litterfall (leaf NPP), above-ground biomass, above-ground fine litter and soil carbon observations}

We used the VAST (Barrett, 2001) database of observations of the above quantities, which were obtained from minimally disturbed sites to ensure a reasonable approximation to steady state conditions. The steady-state approximation allows us to equate litter-fall with NPP allocated to leaves (leaf NPP). The above-ground biomass data set was augmented using additional data compiled by Raison et al. (2003), also for mature native vegetation. About one third of each data set was sub-sampled for parameter estimation, with each subsample containing equal numbers of points from each of the six bioclimatic regions. All the data, as well as recent tropical biomass estimates from D. Hilbert and D. Metcalfe (personal communication, 2012), were used for model evaluation. This led to the following number of points for evaluation (and parameter estimation in parentheses) for each data-type: leafNPP 73 (24); above-ground biomass 175 (54); above ground fine litter 49 (18); soil C 291 (72). 
Table 1. Locations and characteristics of OzFlux sites, and the time-periods used for BIOS2 evaluation and, where applicable, parameter estimation.

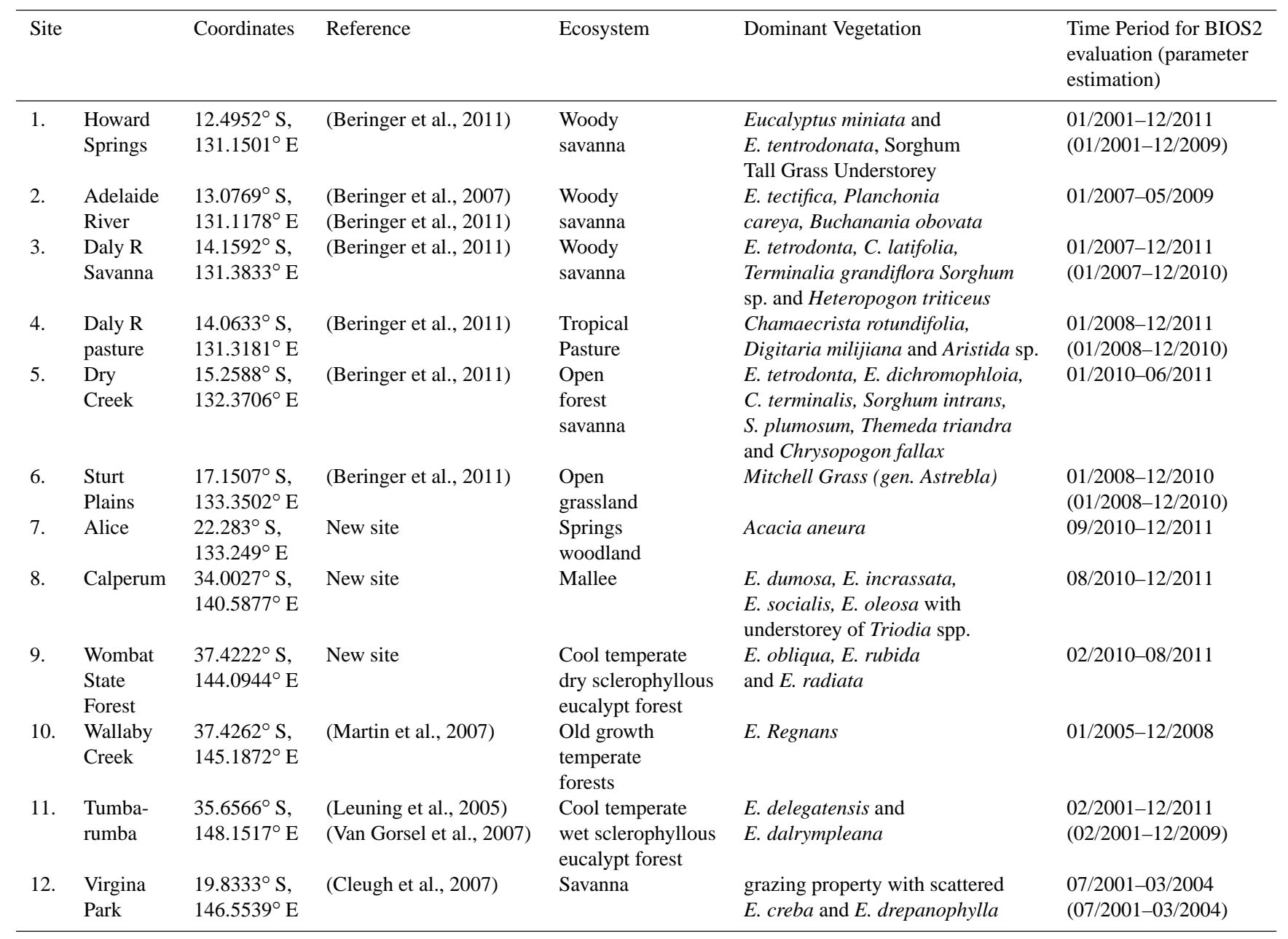

BIOS2 estimates of soil carbon were independently evaluated against spatially soil carbon product, re-sampled from $0.01^{\circ}$ to $0.05^{\circ}$ resolution (hereafter VR-2012). This map was derived using spectroscopic measurements of soil organic $\mathrm{C}$ and soil bulk density and using predictive spatial modeling to develop relationships between soil organic $\mathrm{C}$ density and a suite of environmental variables that accounted for climate, vegetation, soil type and geology, topography and land use.

\subsubsection{Regionally-based carbon budget estimates for three forest ecosystems}

Previous estimates of regional carbon budget components for three forest ecosystems were compared with BIOS2 predictions (Victorian Eucalyptus regnans forests $\left(2324 \mathrm{~km}^{2}\right)$; NSW Coastal Corymbia maculata forests $\left(58 \mathrm{~km}^{2}\right)$; and Queensland poplar-box (Eucalyptus populnea) woodlands $\left.\left(2812 \mathrm{~km}^{2}\right)\right)$. For each comparison a GIS layer of the regional extent of each forest type was intersected with the appropriate $0.05^{\circ} \mathrm{BIOS} 2$ output layer, and the mean and standard de- viation of BIOS2 predictions over that spatial extent calculated.

Estimates of $E$. regnans litterfall were obtained from data in Polglase et al. (1994), based on a review of field-based litterfall estimates for a range of sites across Victoria. The estimate of net primary productivity (NPP) was then obtained by combining the litterfall estimates Polglase et al. (1994) with forest growth curve analyses based on data from Grierson et al. (1992), Dean et al. (2003) and Ashton (1976). NPP

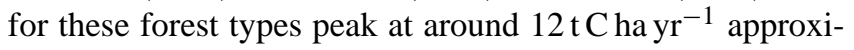
mately $50 \mathrm{yr}$ after stand-replacing fire, declining to approximately $8 \mathrm{tC}^{\mathrm{C}}$ ha $\mathrm{yr}^{-1}$ after $150 \mathrm{yr}$.

Because E. regnans forests are fire sensitive, total living biomass is also a function of time since the last fire. For total living biomass, the range of $285-460 \mathrm{tCha}^{-1}$ corresponds to long-term average carbon storage under fire regimes with return intervals of 150 and $300 \mathrm{yr}$, respectively (Dean et al., 2003), reflecting uncertainty on the unknown regional-scale fire interval history. 
The carbon balance components for the coastal C. maculata forests are from Roxburgh et al. (2006b), and were estimated by fitting an equilibrium carbon balance model using a range of observational carbon stock and flux data as constraints (above-ground biomass and litter and NPP).

The regional estimates of the Poplar Box woodlands (Roxburgh et al., 2006a) are based on a similar methodology to that described in Roxburgh et al. (2006b), but with the model extended to include both grassy and woody vegetation components (Roxburgh, 2005).

\subsection{Parameter and uncertainty estimation}

We used model-data fusion, in the form of formal parameter estimation, to (i) construct a parameter set, which ensures consistency between model predictions and observations; and (ii) construct parameter covariances for use in estimating uncertainties in model predictions. To avoid excessive computational demand, parameter estimation was performed successively for CABLE-SLI and CASA-CNP (with CASA-CNP being driven using output from the optimised CABLE-SLI model). For both models, the model runs required for the parameter estimation process included the full spin-up period. For CABLE-SLI parameter estimation, we used leaf-NPP (litterfall), eddy flux and streamflow observations, while for CASA-CNP we used leaf-NPP and carbon pool data. Based on parameter sensitivity analysis, eight parameters in CABLE-SLI and 15 parameters in CASA-CNP were selected as target parameters, with prior values set according to literature (see Appendix B).

The search algorithm was the Levenberg-Marquardt method implemented in the PEST software package (Doherty, 2004). The cost function to be minimised was the weighted sum of squared residuals, $\Phi=\sum_{i} w_{i}^{2} r_{i}^{2}$, where the residual $r_{i}$ can be either the residual between a model prediction and corresponding observation, or the residual between prior and posterior parameters. Relative observation weights $\left(w_{i}\right)$ were set such that each observation data type contributed equally to the prior cost function, while relative prior parameter weights were set in inverse proportion to their prior uncertainty $(1 \sigma)$. Within each data type (except for eddy flux data), uniform sampling of observations across bioclimatic regions ensured that results were not weighted towards any one region. For eddy flux data, observation weights were prescribed such that each flux site contributed equally to the prior cost function, irrespective of the observation record length.

The parameter covariance matrix was evaluated as

$$
\mathbf{C}(p)=(\Phi /(m-n))\left(\mathbf{J}^{\mathrm{T}} \mathbf{Q J}\right)^{-1}
$$

where $m$ is the number of observations, $n$ the number of parameters being estimated, $\mathbf{J}$ is the Jacobian matrix (with elements $J_{i j}$ the derivatives of the $i$-th observation with respect to the $j$-th parameter), $\mathbf{Q}$ is the diagonal cofactor matrix, with $i$-th diagonal element equal to the square of the $i$-th observation weight $\left(w_{i}^{2}\right)$, and $\mathrm{T}$ denotes a matrix transpose. Thus $\mathbf{C}$ is a mapping of residuals onto parameter covariance using the model Jacobian.

While parameter errors, observation errors and model structural errors are not accounted for separately, their combined effect is realised in the residuals between model predictions and observations, and hence in the cost function. Thus "parameter uncertainties" encapsulate all three of these types of errors.

Uncertainty in model predictions (at the scale of bioclimatic regions, Fig. 1), due to parameter uncertainty and uncertainty in forcing data were estimated separately and combined in quadrature to give total uncertainty. To obtain uncertainties in model predictions associated with parameter uncertainties in a parameter set $p, \mathbf{C}$ was projected onto the variance in the prediction $Z$ :

$\sigma_{Z}^{2}=\left(\frac{\overline{\partial Z}}{\partial p}\right)^{\mathrm{T}} \mathbf{C} \frac{\overline{\partial Z}}{\partial p}$

where $\overline{\partial Z / \partial p}$ is the vector of sensitivities of a prediction $Z$ to the elements of $p$. Parameter sensitivities were determined numerically by evaluating perturbations to regionally averaged model output resulting from parameter perturbation. The computational demand of this process was reduced by performing the required model runs on a stratified random sample of $1000\left(0.05^{\circ} \times 0.05^{\circ}\right)$ gridcells $(0.3 \%$ of the continent, Fig. 3).

Uncertainties in model predictions associated with forcing uncertainties were estimated as the absolute change in prediction associated with perturbations to forcing inputs. These were summed in quadrature to give the total forcing uncertainty. For CABLE-SLI, we perturbed meteorological, vegetation cover and soil input data. Meteorological inputs were perturbed by the following estimated $1 \sigma$ uncertainties: precipitation $(10 \%)$; incoming solar radiation $(10 \%)$; air temperature $\left(1^{\circ} \mathrm{C}\right)$; vapour pressure $(10 \%)$; and wind speed $(50 \%)$.Vegetation cover was perturbed by switching from LAI derived from AVHRR fPAR to that derived from MODIS fPAR. Soil input data were perturbed by randomly permuting the locations of the soil principle profiles, while maintaining their frequency distribution. Forcing uncertainties in CASA-CNP predictions were estimated by perturbing the inputs (derived from CABLE-SLI). They represent an upper limit to the uncertainties propagated from CABLESLI to CASA-CNP, because CASA-CNP parameters were not re-optimised for each perturbation of CABLE-SLI input. NPP and the fraction of NPP attributable to grassy vegetation were perturbed by the derived $1 \sigma$ uncertainties in these variables (Sect. 5.1, Fig. 11). Volumetric soil moisture content was perturbed by $10 \%$ and soil temperature by $2{ }^{\circ} \mathrm{C}$. In addition, the model initialisation was perturbed by substituting the spin-up period of 1970-1989 with the 1950-1969 period. 


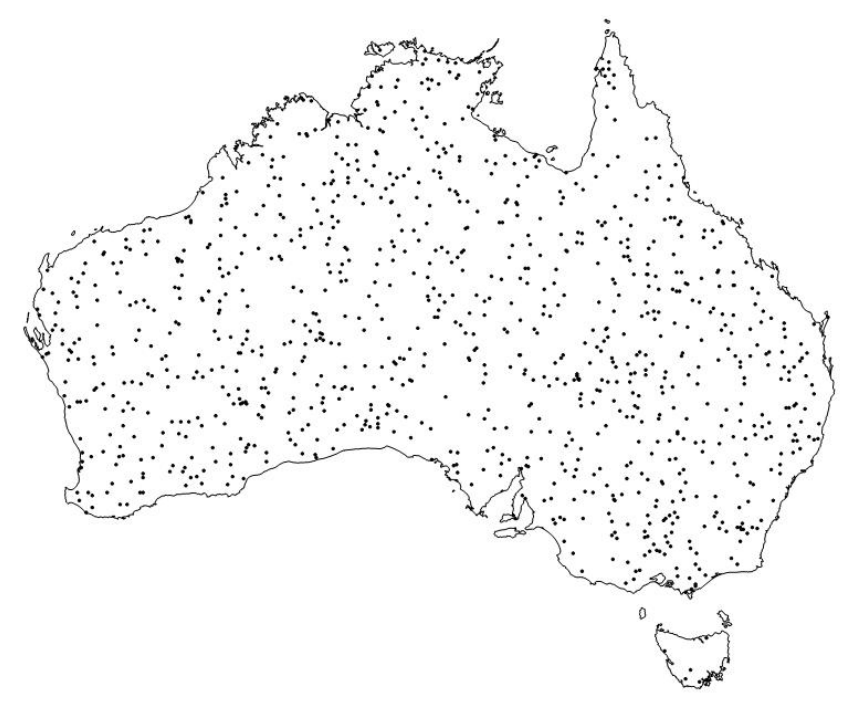

Fig. 3. Location of 1000 grid-cells, selected such that their cumulative distribution of modelled NPP matched that of the whole continent. (For use in sensitivity analyses).

\section{Parameter estimation results}

\subsection{Constraints from multiple observation sets}

Figure 4 shows the impact of each of three observation sets (leaf NPP from litterfall, streamflow and eddy flux data) and combinations thereof on the long-term mean Australian continental NPP estimate and its uncertainty.

Prior parameters and their uncertainties $(1 \sigma)$ lead to a continental NPP of $2.5 \pm 1.1 \mathrm{PgC} \mathrm{yr}^{-1}$, while the estimate constrained by all three data sets is $2.2 \pm 0.4 \mathrm{Gt} \mathrm{C} \mathrm{yr}^{-1}$, indicating a strong constraint by the observations. Each data set individually leads to a reduction in uncertainty compared with the prior estimate, although with different values, reflecting possible biases in the model and/or observations for particular observables. The estimates are more convergent when two observation sets are used simultaneously, and the estimate constrained by all three is a compromise between the results obtained using each data set individually.

The error bars in Fig. 4 indicate that eddy flux data provide a stronger constraint than leaf NPP, even though leaf NPP observations were more widely distributed (Fig. 2). This reflects the high precision of the eddy flux measurements compared with disparate litterfall observations which do not share a common methodology and are subject to large errors from fine scale heterogeneity. Long-term evaporation estimated as the difference between rainfall and streamflow provides a relatively weak constraint because in most regions of Australia, it is largely driven by rainfall (continentally, evaporation accounts for $90 \%$ of precipitation). Temporal dynamics of streamflow may provide a stronger constraint than the long-term mean, but only if the model accurately represents

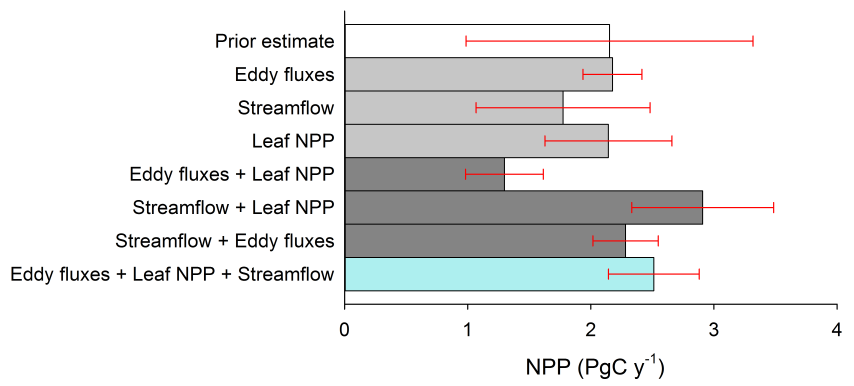

Fig. 4. Mean (1990-2011) Australian continental NPP estimates, obtained using prior parameters and 7 parameter sets obtained by using different observation sets and combinations thereof in the parameter estimation procedure. Error bars represent the 1- $\sigma$ uncertainty attributable to parameter variance and covariance, calculated using Eq. (3).

the transmission of runoff and deep drainage to stream at the time scale of the aggregated observations.

Although the uncertainty estimate on NPP under constraint from all three data types is not the lowest of all uncertainties in Fig. 4, we maintain this as our best estimate of continental NPP, and use the corresponding parameter set throughout this work. The reason is that the error bars reflect residuals between observations and predictions via Eq. (3), but not unquantified biases in the observations. Adopting the parameter set and corresponding predictions constrained by all three data types mitigates against results being biased by any single data type. Examples of sources of observation bias include: (i) herbivory which would reduce litterfall compared with leaf-NPP; (ii) offtakes of water from streams which are assumed unimpaired (without offtakes for human consumption), leading to over-estimation of ET from observations; (iii) underestimation of $\mathrm{CO}_{2}$ exchange at eddy flux sites, particularly at nighttime, leading to an over-estimate of observed $\mathrm{GPP}^{\prime}$.

We also investigated the impact of the data constraints on the parameter component of uncertainty in long-term predictions of four other variables: (i) the fraction of NPP attributable to recurrent (mainly grassy) vegetation $\left(\mathrm{NPP}_{g} / \mathrm{NPP}\right)$; (ii) ET; (iii) the fraction of ET attributable to soil evaporation $\left(E_{\text {Soil }} / \mathrm{ET}\right)$; and (iv) the fraction of precipitation converted to runoff (Runoff/Precip). Results are given in Table A1. Relative prior uncertainties decrease in order $\mathrm{NPP}>\left(\mathrm{NPP}_{\mathrm{g}} / \mathrm{NPP}\right)>\left(E_{\text {soil }} / \mathrm{ET}\right)>($ Runoff/Precip $)>$ ET . Similar to the results for NPP, we find that, for all four quantities: (i) the eddy flux data alone the strongest constraint of the three data types; (ii) each data set individually leads to a reduction in uncertainty compared with the prior estimate; (iii) the estimate constrained by all three is a compromise between the results obtained using each data set individually, but with a larger uncertainty than that obtained using eddy flux data alone. Streamflow observations constrain ET and Runoff/Precip more strongly than leaf NPP observations 
Table 2. Statistics relating to scatterplots of BIOS2 predictions $(y)$ vs. observations $(x)$.

\begin{tabular}{|c|c|c|c|c|c|c|c|}
\hline Time scale & observable & $n$ & $R^{2}$ & $\mathrm{RMSE}^{\mathrm{a}}$ & $\mathrm{NRMSE}^{\mathrm{b}}$ & $\mathrm{NMAE}^{\mathrm{c}}$ & MARE $^{\mathrm{d}}$ \\
\hline \multirow{4}{*}{$\begin{array}{l}\text { Ensemble- } \\
\text { monthly } \\
\text { mean }\end{array}$} & $\begin{array}{l}\mathrm{ET} \\
\left(\mathrm{mm} \mathrm{d}^{-1}\right)\end{array}$ & 144 & 0.80 & 0.55 & 0.45 & -0.007 & 0.45 \\
\hline & $\begin{array}{l}\mathrm{GPP}^{\prime} \\
\left(\mathrm{gC} \mathrm{m}^{-2} \mathrm{~d}^{-1}\right)\end{array}$ & 144 & 0.80 & 1.2 & 0.47 & -0.11 & 0.57 \\
\hline & $\begin{array}{l}\text { NEP anomaly } \\
\left(\mathrm{g} \mathrm{C} \mathrm{m}^{-2} \mathrm{~d}^{-1}\right)\end{array}$ & 144 & 0.59 & 0.54 & 0.69 & - & - \\
\hline & $\begin{array}{l}\text { Total WUE }\left(\mathrm{GPP}^{\prime} / \mathrm{ET}\right) \\
\left(\mathrm{g} \mathrm{C} \mathrm{kg}^{-1} \mathrm{H}_{2} \mathrm{O}\right)\end{array}$ & 144 & 0.58 & 0.74 & 0.68 & -0.10 & 0.43 \\
\hline \multirow[t]{4}{*}{$\begin{array}{l}\text { Annual } \\
\text { mean }\end{array}$} & $\begin{array}{l}\mathrm{ET} \\
\left(\mathrm{mm} \mathrm{d}^{-1}\right)\end{array}$ & 51 & 0.71 & 0.44 & 0.58 & -0.05 & 0.17 \\
\hline & $\begin{array}{l}\mathrm{GPP}^{\prime} \\
\left(\mathrm{gC} \mathrm{m}^{-2} \mathrm{~d}^{-1}\right)\end{array}$ & 51 & 0.87 & 0.89 & 0.39 & -0.1 & 0.23 \\
\hline & $\begin{array}{l}\text { NEP anomaly } \\
\left(\mathrm{g} \mathrm{C} \mathrm{m}^{-2} \mathrm{~d}^{-1}\right)\end{array}$ & 51 & 0.1 & 0.58 & 0.99 & - & - \\
\hline & $\begin{array}{l}\text { Total WUE }\left(\mathrm{GPP}^{\prime} / \mathrm{ET}\right) \\
\left(\mathrm{g} \mathrm{C} \mathrm{kg}^{-1} \mathrm{H}_{2} \mathrm{O}\right)\end{array}$ & 51 & 0.85 & 0.33 & 0.40 & -0.04 & 0.21 \\
\hline \multirow{5}{*}{$\begin{array}{l}\text { Long- } \\
\text { term } \\
\text { (several } \\
\text { years) } \\
\text { mean }\end{array}$} & $\begin{array}{l}\mathrm{ET} \\
\left(\mathrm{mm} \mathrm{d}^{-1}\right)\end{array}$ & 364 & 0.69 & 0.30 & 0.52 & -0.0142 & 0.092 \\
\hline & $\begin{array}{l}\text { Litter-fall } \\
(\mathrm{tC} \mathrm{ha} \\
\left.-1 \mathrm{yr}^{-1}\right)\end{array}$ & 73 & 0.36 & 1.2 & 0.80 & 0.006 & 1.1 \\
\hline & $\begin{array}{l}\text { Above-ground biomass } \\
\left(\mathrm{tCha}^{-1}\right)\end{array}$ & 175 & 0.58 & 59 & 0.66 & -0.13 & 2.3 \\
\hline & $\begin{array}{l}\text { Above-ground fine litter } \\
\left(\mathrm{tCha}^{-1}\right)\end{array}$ & 49 & 0.10 & 6.3 & 0.96 & -0.01 & 0.89 \\
\hline & $\begin{array}{l}\text { Soil carbon density (top } 15 \mathrm{~cm} \text { ) } \\
\left(\mathrm{g} \mathrm{C} \mathrm{kg}^{-1}\right)\end{array}$ & 291 & 0.19 & 67 & 0.94 & -0.42 & 1.2 \\
\hline
\end{tabular}

do, while the reverse is true for the constraints on NPP, $\mathrm{NPP}_{\mathrm{g}} / \mathrm{NPP}$ and $E_{\text {soil }} / \mathrm{ET}$.

\subsection{Parameters: prior and posterior estimates, covariances and sensitivities}

Prior and posterior parameter estimates, and the sensitivities of key model predictions to these parameters, are given in Table A2 (CABLE-SLI) and Table A3 (CASA-CNP). Uncertainty in all the CABLE-SLI target parameters is reduced by the parameter estimation process (Table A2). Relative sensitivities indicate a strong dependence of NPP and soil evaporation on the parameters $\log (\gamma)$ and $D_{\mathrm{s} 0}$, which control the response of stomatal conductance to soil moisture and humidity deficit, respectively. These sensitivities are particularly high in the tropics, savanna and desert regions. Continental NPP has a weak relative sensitivity $(0.12)$ to $\mathrm{V}_{\mathrm{C}, \max }^{25}$ for woody vegetation, although this sensitivity is much higher $(\sim 0.25)$ for the temperate regions where water limitation is less severe than elsewhere. There is weak nega- tive sensitivity of continental NPP to $\mathrm{V}_{\mathrm{C} \text {,max }}^{25}$ for grassy vegetation, the result of higher modelled grassy photosynthetic activity when soil moisture is plentiful, leading to more severe soil moisture deficit later in the growing season.

Target parameters in CASA-CNP were only weakly constrained by the data. Uncertainty reductions in 5 of the 15 target parameters were achieved by the parameter estimation process: these were the mean ages of $\mathrm{C}$ in slow soil turnover $\mathrm{C}$ pool, the structural litter pool and woody biomass, and leaf carbon allocation coefficients (woody and grassy).

Parameter covariances (off-diagonal terms in C, Eq. 3) are important because they reduce uncertainty in model predictions, relative to the prior assumption of uncorrelated parameters. Parameter correlation coefficient matrices for CABLESLI and CASA-CNP are given in Appendix D. High absolute values between two parameters indicate that their values cannot be resolved by the observations. Note the strong correlation between $\log (\gamma)$ and $\mathrm{V}_{\mathrm{C} \text {,max }}^{25}$ for grass, consistent with carbon uptake by grass being strongly regulated by soil 
moisture availability. The parameter correlation matrix for CASA-CNP is much sparser than for CABLE-SLI, reflecting more direct relationships between parameters and observations. Here, large correlations exist between (i) the leaf turnover time (woody) and the base turnover time of fine litter (co-determining the size of the fine litter observable); (ii) the base turnover time of the largest soil pool and the fraction of soil carbon in the top $10 \mathrm{~cm}$ (co-determining the soil carbon density observable); and (iii) the fraction of carbon allocated to wood and the turnover time of woody biomass (co-determining the above-ground biomass observable).

\section{BIOS2 model evaluation against observations}

\subsection{Carbon and water fluxes at Ozflux sites}

Figures 5 and 6 show continental maps of ET and GPP (1990-2011 mean) and locations of the 12 flux stations, along with ensemble monthly mean ET and GPP' (observed and BIOS2), gridded precipitation and LAI (from MODIS fPAR) at each site. The maps indicate that the site fluxes encompass almost the entire continental range for ET, but not the highest GPP values. Model evaluation statistics are listed in Table 2. Figure 7 displays the same ensemble mean monthly fluxes of GPP' and ET (along with NEP anomaly and total WUE) in the form of $x-y$ scattergrams, while Figure 8 displays annual values of the same quantities.

Several results emerge from Figs. 5-8 and Table 2: (i) BIOS2 captures $79 \%, 78 \%, 52 \%$ and $57 \%$ (respectively) of the variances in observed in the mean annual cycles of ET, $\mathrm{GPP}^{\prime}$, NEP anomaly and WUE; (ii) BIOS2 performs well both for seasonal cycles of ET and $\mathrm{GPP}^{\prime}$ in regions driven both by monsoonal rainfall seasonality (Sites 1-6,12) and by radiation seasonality (cool-temperate sites 9-11); (iii) At the northern grass-covered sites (Daly River Pasture (4) and Sturt Plains (6)), observed ET and GPP' decline to zero in the dry season, but are over-predicted by BIOS2, owing to the LAI apparently persisting through the dry season (Fig. 6) and being attributed to woody vegetation with access to deep soil moisture; (iv) Conversely at 3 woody savanna sites $(1,3,5)$, the predicted dry-season ET and/or GPP' is too low. This is because the algorithm for partitioning LAI indicates a significant recurrent component in the dry season. For example, from July to August at Howard Springs, "recurrent" LAI derived from MODIS PPAR accounts for $\sim 0.5$ of the total. Because of our assumption that the derived recurrent fraction of LAI is attributable to grass and because the grass is relatively shallow-rooted, a large fraction of the model vegetation cover becomes severely water limited in the dry season. This leads to an underprediction of ET and GPP, even though modelled soil moisture deficit, reduces stomatal conductance by at most $20 \%$ for the deep-rooted woody vegetation at these sites. Site observations of LAI components at Howard Springs (Hutley et al., 2000) support this explana- tion. (v) There is significant over-prediction of WUE at the northern grass-covered sites (Daly River Pasture (4) and Sturt Plains (6)) and at Virigina Park, where dry-season GPP' is over-predicted; (vi) BIOS2 annual predictions (Fig. 5) capture $68 \%, 91 \%, 14 \%$ (40\% if Tumbarumba is excluded) and $85 \%$ of observed variance in ET, GPP', NEP anomaly and WUE, respectively (Fig. 8); (vi) At Daly R savanna and Howard Springs, BIOS2 significantly underestimates interannual variability (IAV) in ET, possibly indicating insufficient sensitivity of modelled ET to soil moisture or a lack of accurate inter-annual assessment of LAI at these sites; (vii) At Tumbarumba, IAV in annual ET and GPP' was also significantly underestimated. The latter translates directly to underestimation in IAV in annual NEP.

The high IAV in the observed fluxes at Tumbarumba can be largely explained by an insect attack that occurred during the summer 2002-2003 (Keith et al., 2012). Tree leaves were damaged, reducing photosynthetically active leaf area (although curiously this is not evident in the remotely-sensed fPAR used in BIOS2, from either AVHRR or MODIS). Due to dry conditions the regenerative capacity to replace damaged leaves was limited and the usually highly productive forest turned into a carbon source for several months (van Gorsel et al., 2008). Interannual variability in observed soil water content in the top $120 \mathrm{~cm}$ has little impact on GPP (unpublished data), consistent with BIOS2 predictions. In future work, attribution of observed IAV to a range of drivers (e.g. soil moisture, radiation, temperature, disturbance) would be useful for the attribution of modelobservation discrepancies in IAV.

In other studies, observations from the Howard Springs site have been used to estimate the carbon balance of a tropical savanna (Chen et al., 2003), and to constrain a model of GPP and transpiration fluxes at the site (Whitley et al., 2011). Chen et al. (2003), estimated $\mathrm{C}$ pools in biomass, litter and soil to be $50 \pm 20,1.9 \pm 0.9$ and $151 \pm 32 \mathrm{tCha}^{-1}$, respectively. Corresponding respective BIOS2 estimates of 76, 5.4 and $289 \mathrm{tC} \mathrm{ha}^{-1}$ are likely to be higher because the reduction in turnover time due to fire is not explicitly accounted for. The GPP estimate of $5.7 \mathrm{~g} \mathrm{C} \mathrm{m}^{-2} \mathrm{~d}^{-1}$ from the same study is higher than the BIOS2 estimate (1990-2011) of $3.3 \mathrm{~g} \mathrm{C} \mathrm{m}^{-2} \mathrm{~d}^{-1}$ by a factor of 1.7. However GPP' (averaged over observation years) derived from flux data is only a factor of 1.2 higher than the BIOS2 estimate, indicating a discrepancy between the two observation-based estimates. Whitley et al. (2011) produce a modelled GPP of $3.9 \mathrm{~g} \mathrm{C} \mathrm{m}^{-2} \mathrm{~d}^{-1}$, in accord with the eddy flux data used to constrain their model, and a $38 \%$ contribution from the $\mathrm{C} 4$ grass component, in good agreement with the estimate of $43 \%$ from BIOS2.

\subsection{Long-term observations of ET, leaf-NPP and carbon pools}

Figure 9 shows model performance against long-term observations, with evaluation metrics in Table 2. BIOS2 performs 

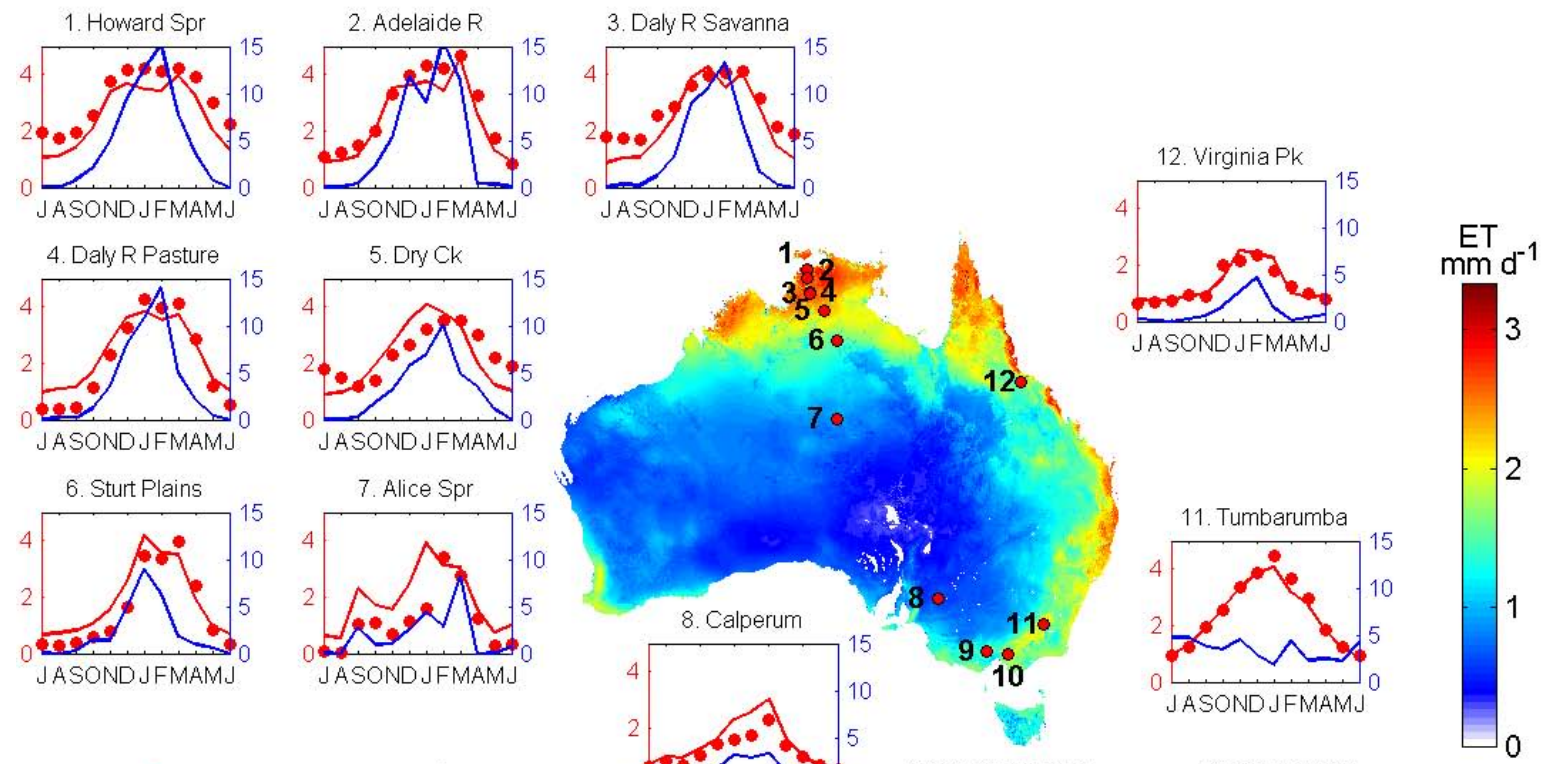

- ET (obs) [mm d $\left.{ }^{-1}\right]$

ET (BIOS2) [ $\left.\mathrm{mm} \mathrm{d}^{-1}\right]$

precip $\left[\mathrm{mm} \mathrm{d}^{-1}\right]$
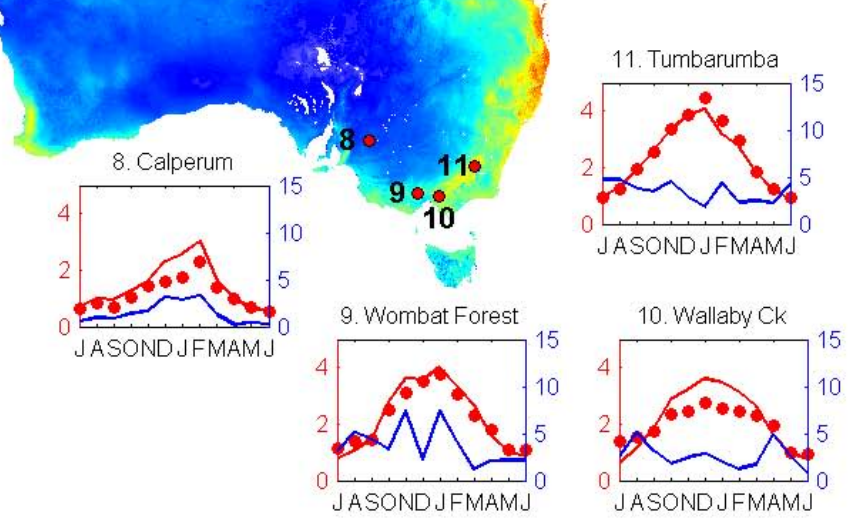

Fig. 5. Mean (1990-2011) ET (map), ensemble monthly mean ET (averaged over years of obs) (BIOS2 and obs, left axis) and gridded precipitation (right axis) at 12 OzFlux sites.
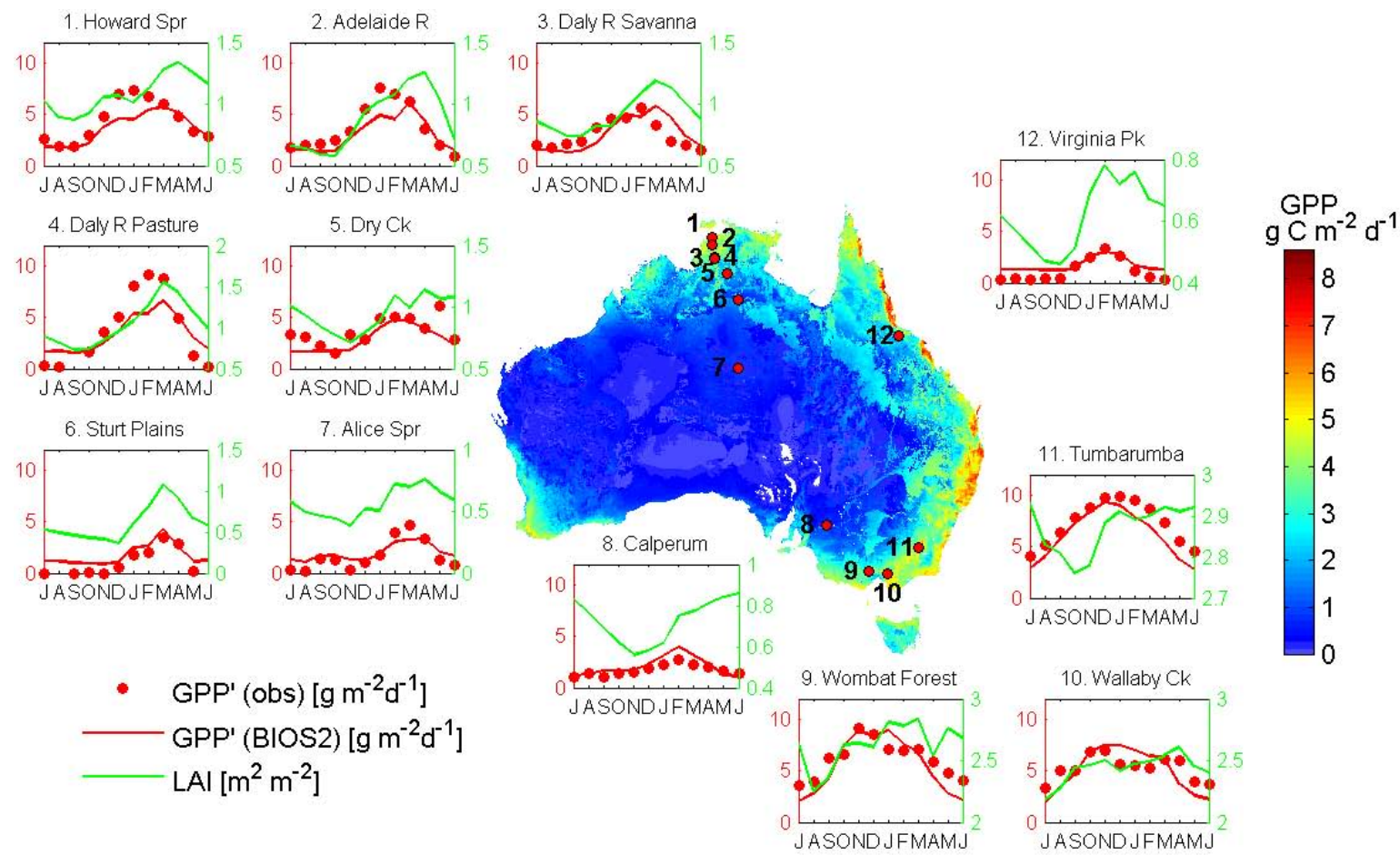

Fig. 6. Mean (1990-2011) GPP (map), mean annual cycle (averaged over years of obs) of GPP' (BIOS2 and obs, left axis) and LAI (right axis) at 12 OzFlux sites. 

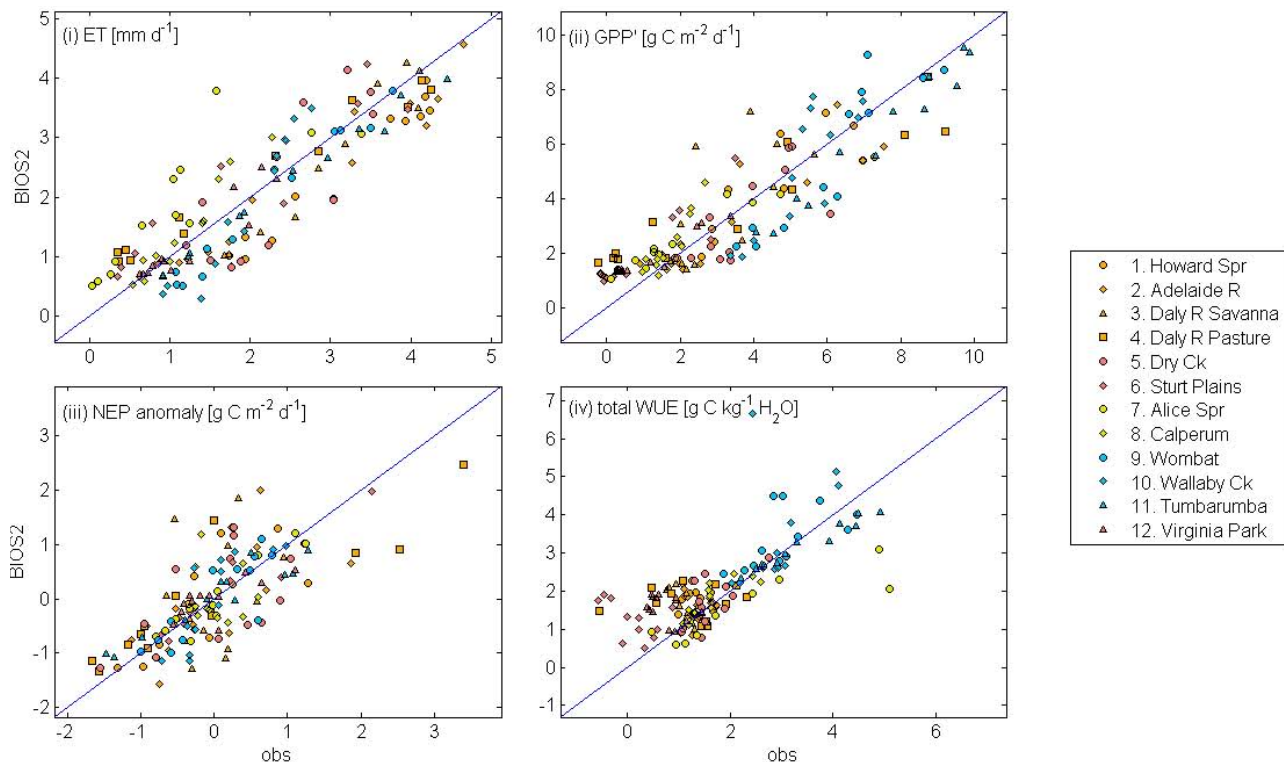

Fig. 7. Scatterplots of ensemble monthly mean (averaged over obs years) model predictions vs Ozflux observations of (i) ET; (ii) GPP'; (iii) NEP anomaly; and (iv) total WUE (= GPP'/ET).
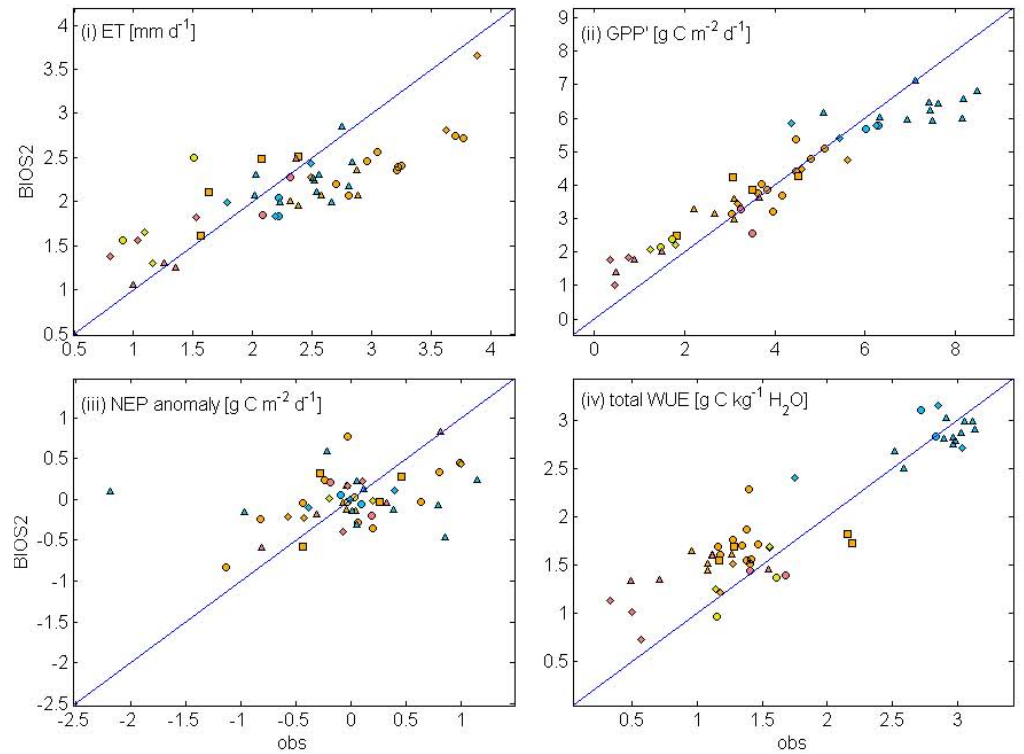

$$
\begin{aligned}
& \text { - 1. Howard Spr } \\
& \text { 2. Adelaide R } \\
& \text { - 3. Daly R Savanna } \\
& \text { a 4. Daly R Pasture } \\
& \text { - 5. Dry CK }
\end{aligned}
$$

Fig. 8. Scatterplots of annual BIOS2 predictions vs Ozflux observations of (i) ET; (ii) GPP'; (iii) NEP anomaly; and (iv) total WUE $\left(=\mathrm{GPP}^{\prime} / \mathrm{ET}\right)$.

similarly against long-term ET from streamflow (Fig.9i) and annual ET from eddy flux data (Fig. 8i). The relationships between model predictions and observations for leaf-NPP and the carbon pools are highly scattered, and it is not easy to identify whether this is because the model underestimates spatial heterogeneity and/or because the observations are imprecise. Nonetheless, as we will demonstrate in Sect. 5, regional biases for any of these observables are mostly within $\pm 1 \sigma$ uncertainty estimates of the predicted re- gional mean. There is also some indication of a systematic bias in cool temperate productivity, with cool temperate ET, above-ground biomass, fine litter and soil carbon all sharing a bias towards under-prediction.

Figure 10 explores the spatial differences between BIOS2 and VR2012 soil carbon density. Comparison of the maps reveals similar spatial patterns, but with BIOS2 having lower values, than VR2012 particularly in the desert. These differences are quantified by region in the frequency histograms 

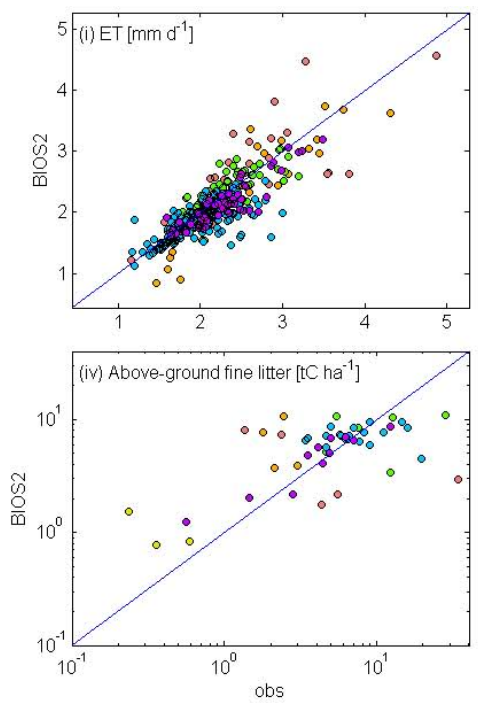
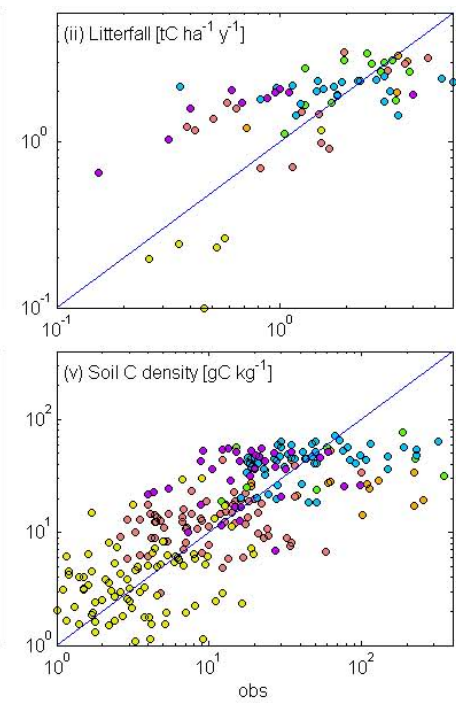
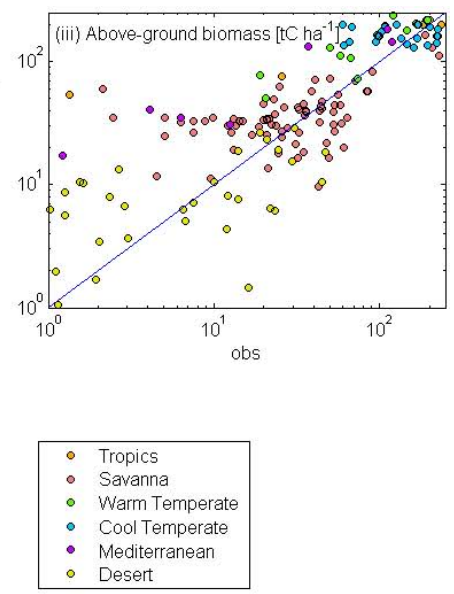

- Savann

Warm Temperate

- Desert

Fig. 9. Scatter plots of long-term model predictions vs observations of (i) catchment-scale ET derived from streamflow; (ii) leaf-NPP (litterfall); (iii) above ground biomass; (iv) above ground fine litter; and (v) soil carbon density in the top $15 \mathrm{~cm}$.

and bar chart. The frequency distributions of BIOS2 soil carbon in the tropics, savanna and Mediterranean regions show two peaks associated with woody and grassy vegetation types, which are not evident in the VR2012 data. Structure in the BIOS2 desert frequency distribution was caused largely by variation in soil type which strongly modulates total water use efficiency. For example, fast-draining sandy soils in the desert are associated with very low soil moisture available to roots and hence low NPP. Resulting very low values of BIOS2 desert soil carbon are not present in VR2012. Overall, BIOS2 predictions of soil carbon density are biased low by 29 \% compared to VR2012, and the spatial correlation across all grid cells is $R^{2}=0.66$.

\subsection{Comparison of BIOS2 predictions with independent regionally-based carbon budget estimates for three forest ecosystems}

Comparisons of regionally based carbon budget components (spatial standard deviations in parentheses) with BIOS2 predictions are given in Table 3 for three forest ecosystems. The BIOS2 NPP for $E$. regnanslies within the empirically derived range of 8.0-12.0 $\mathrm{tC} \mathrm{ha}^{-1} \mathrm{yr}^{-1}$. The BIOS2 estimate of total living biomass $\left(178.03 \mathrm{t} \mathrm{Cha}^{-1}\right)$ falls below the lower bound of $285 \mathrm{tC} \mathrm{ha}^{-1}$ based on the assumed long-term mean fire return interval of $150 \mathrm{yr}$.

For the coastal C. maculata forests, there is reasonable agreement for the flux components, but discrepancy for the carbon pools. The lower predictions of litter and biomass may be due to particular characteristics of this forest type that are unable to be captured by the broad parameterisation of BIOS2 necessary to facilitate continental analysis. In particular, C. maculata trees have a relatively high wood basic density (approximately 0.8 ), contributing to high biomass per unit ground area, and the litter stocks in these forests can be very high due to coarse woody debris derived from fallen trees, which are resistant to decay.

For regional estimates of the Poplar Box woodlands, the BIOS2 predictions of the carbon balance components are generally close to those for the regional study, with the major difference being a higher soil carbon stock. One reason for soil carbon being higher in BIOS2 than the regionallyspecific study is that, while there is reasonable agreement between litter decay rates, the microbial efficiency (or fraction of turned-over litter carbon which is respired) is much lower.

\subsection{Herbage yield in arid rangelands}

Estimates of precipitation-use-efficiency (PUE) (aboveground NPP divided by annual rainfall) are available for Australian arid and semi-arid grazed rangelands $(<600 \mathrm{~mm})$, which occupy $33 \%$ of the continent. As documented by Roxburgh et al. (2004), observations of above-ground herbage production in the absence of either grazing or competition from woody plants indicate yields of around $1.0 \mathrm{~kg} \mathrm{Cha}^{-1} \mathrm{~mm}^{-1}$ in regions of low rainfall (230-260 $\mathrm{mm} \mathrm{yr}^{-1}$ ) and $1.5-2.5 \mathrm{~kg} \mathrm{Cha}^{-1} \mathrm{~mm}^{-1}$ for higher rainfall $\left(500-600 \mathrm{~mm} \mathrm{yr}^{-1}\right)$. Corresponding estimates of precipitation-use-efficiency from BIOS2 were obtained by averaging across gridcells with less than $10 \%$ woody vegetation cover in each of the low $\left(230-260 \mathrm{~mm} \mathrm{yr}^{-1}\right)$ and higher (500-600 $\mathrm{mm} \mathrm{yr}^{-1}$ ) rainfall ranges. Respective results of $1.5 \pm 0.5$ and $1.9 \pm 0.5 \mathrm{~kg} \mathrm{Cha}^{-1} \mathrm{~mm}^{-1}$ agree well with the above observation-based estimates. Here BIOS2 uncertainties $(1 \sigma)$ represent spatial variation. 
Table 3. Comparison of regionally-based carbon budget components for three forest ecosystems with BIOS2 predictions.

\begin{tabular}{|c|c|c|c|c|c|c|}
\hline \multirow[t]{2}{*}{ Variable } & \multicolumn{2}{|c|}{$\begin{array}{l}\text { Victorian } \\
\text { Eucalyptus regnans } \\
\text { forests }\left(2324 \mathrm{~km}^{2}\right)\end{array}$} & \multicolumn{2}{|c|}{$\begin{array}{l}\text { Queensland poplar- } \\
\text { box woodlands } \\
\left(2812 \mathrm{~km}^{2}\right)\end{array}$} & \multicolumn{2}{|c|}{$\begin{array}{l}\text { NSW Coastal } \\
\text { Corymbia maculata } \\
\text { forests }\left(58 \mathrm{~km}^{2}\right)\end{array}$} \\
\hline & BIOS2 & $\begin{array}{l}\text { Regional } \\
\text { estimate }\end{array}$ & BIOS2 & $\begin{array}{l}\text { Regional } \\
\text { estimate }\end{array}$ & BIOS2 & $\begin{array}{l}\text { Regional } \\
\text { estimate }\end{array}$ \\
\hline Total NPP & 8.73 & & 4.82 & 3.47 & 10.64 & 7.09 \\
\hline$\left(\mathrm{tCha}^{-1} \mathrm{yr}^{-1}\right)$ & $(0.52)$ & $8.0-12.0$ & $(0.7)$ & $(0.45)$ & $(0.34)$ & $(0.55)$ \\
\hline Grass NPP & & & 1.88 & & & \\
\hline$\left(\mathrm{tCha}^{-1} \mathrm{yr}^{-1}\right)$ & & & $(0.56)$ & $0.25-1.0$ & & \\
\hline Tree NPP & & & 2.94 & & & \\
\hline$\left(\mathrm{tCha}^{-1} \mathrm{yr}^{-1}\right)$ & & & $(0.44)$ & $2.4-3.15$ & & \\
\hline Litter decay (sum & & & 4.75 & 3.47 & 10.77 & 7.09 \\
\hline $\begin{array}{l}\text { of two terms below) } \\
\left(\mathrm{tCha}^{-1} \mathrm{yr}^{-1}\right)\end{array}$ & & & $(0.72)$ & $(0.45)$ & $(0.35)$ & $(0.55)$ \\
\hline Litter $C$ release & & & 1.30 & 2.22 & 3.40 & 4.02 \\
\hline $\begin{array}{l}\text { to atmosphere } \\
\left(\mathrm{tC} \mathrm{ha}^{-1} \mathrm{yr}^{-1}\right)\end{array}$ & & & $(0.36)$ & $(0.48)$ & $(0.17)$ & $(0.64)$ \\
\hline $\mathrm{C}$ flux from litter to & & & 3.45 & 1.25 & 7.37 & 3.07 \\
\hline soil (soil humification) & & & $(0.45)$ & $(0.17)$ & $(0.23)$ & $(0.64)$ \\
\hline$\left(\mathrm{tCha}^{-1} \mathrm{yr}^{-1}\right)$ & & & & & & \\
\hline Biomass & 178.03 & & 69.75 & 44.8 & 220.61 & 432.84 \\
\hline$\left(\mathrm{tC} \mathrm{ha}^{-1}\right)$ & $(16.60)$ & $285-460$ & $(10.83)$ & $(4.8)$ & $(6.70)$ & $(85.74)$ \\
\hline Soil Stock & & & 250.7 & 53.8 & 430.00 & 225.49 \\
\hline$\left(\mathrm{tCha}^{-1}\right)$ & & & (71.19) & $(6.1)$ & (21.03) & (11.88) \\
\hline Litter Stock & & & 8.47 & 14.41 & 20.27 & 103.30 \\
\hline$\left(\mathrm{tCha}^{-1}\right)$ & & & $(2.14)$ & (2.63) & $(0.74)$ & $(54.21)$ \\
\hline
\end{tabular}

Table 4. Observed soil evaporation flux: total and as a fraction of ET at 3 field sites, and corresponding BIOS2 estimates.

\begin{tabular}{lllrrrr}
\hline site & obs reference & obs period & \multicolumn{2}{c}{$\begin{array}{c}\text { Soil evap } \\
\left(\mathrm{mm} \mathrm{d}^{-1}\right)\end{array}$} & \multicolumn{2}{c}{$\begin{array}{c}\text { Soil evap } \\
\text { fraction }\end{array}$} \\
\cline { 3 - 6 } & & & obs & BIOS2 & obs & BIOS2 \\
\hline Tumbarumba & (Haverd et al., 2011) & Nov-06 (clear sky days) & 0.75 & 0.34 & 0.15 & 0.09 \\
Howard Springs & (Hutley et al., 2000) & Mar-98 & 1.85 & 2.23 & 0.50 & 0.58 \\
Corrigin & (Mitchell et al., 2009) & Mar-06-Feb-07 & 0.42 & 0.42 & 0.44 & 0.52 \\
\hline
\end{tabular}

\subsection{Soil evaporation fraction of total ET}

In contrast to total evaporation, observation-based estimates of the soil evaporation component are sparse. In Table 4, we compile estimates from the literature of soil evaporation and soil evaporation fraction (of total ET) derived from observations at three contrasting sites. The Tumbarumba (cool temperate forest) estimates were derived using a model data fusion approach which included constraints from (i) eddy flux data; (ii) vertical atmospheric profiles of temperature, water vapour and deuterium in water vapour; (iii) turbulence statistics; and (iv) deuterium content of soil evaporation and transpiration fluxes derived from chamber measurements (Haverd et al., 2011). The Howard Springs (tropical savanna) estimates were derived using a combination of eddy flux, sap-flow and open-top chamber methods (Hutley et al., 2000). The Corrigin (mediterranean semi-arid woodland) estimates were derived from a combination of evaporationdome and sap-flow observations (Mitchell et al., 2009).

BIOS2 reproduces: (i) the low fraction of soil evaporation at Tumbarumba, where soil evaporation is suppressed by litter cover; (ii) the high soil evaporation fraction at Howard Springs during the wet season when the surface soil is persistently wet and (iii) high annual soil evaporation fraction at Corrigin, where vegetation cover is sparse with no understorey. The BIOS2 soil evaporation fraction differs from the observed estimate by up to 0.08 , in-line with BIOS2 regional uncertainty estimates (Sect. 5.1 below) of soil evaporation fraction $(0.05-0.07 ; 1 \sigma)$. 

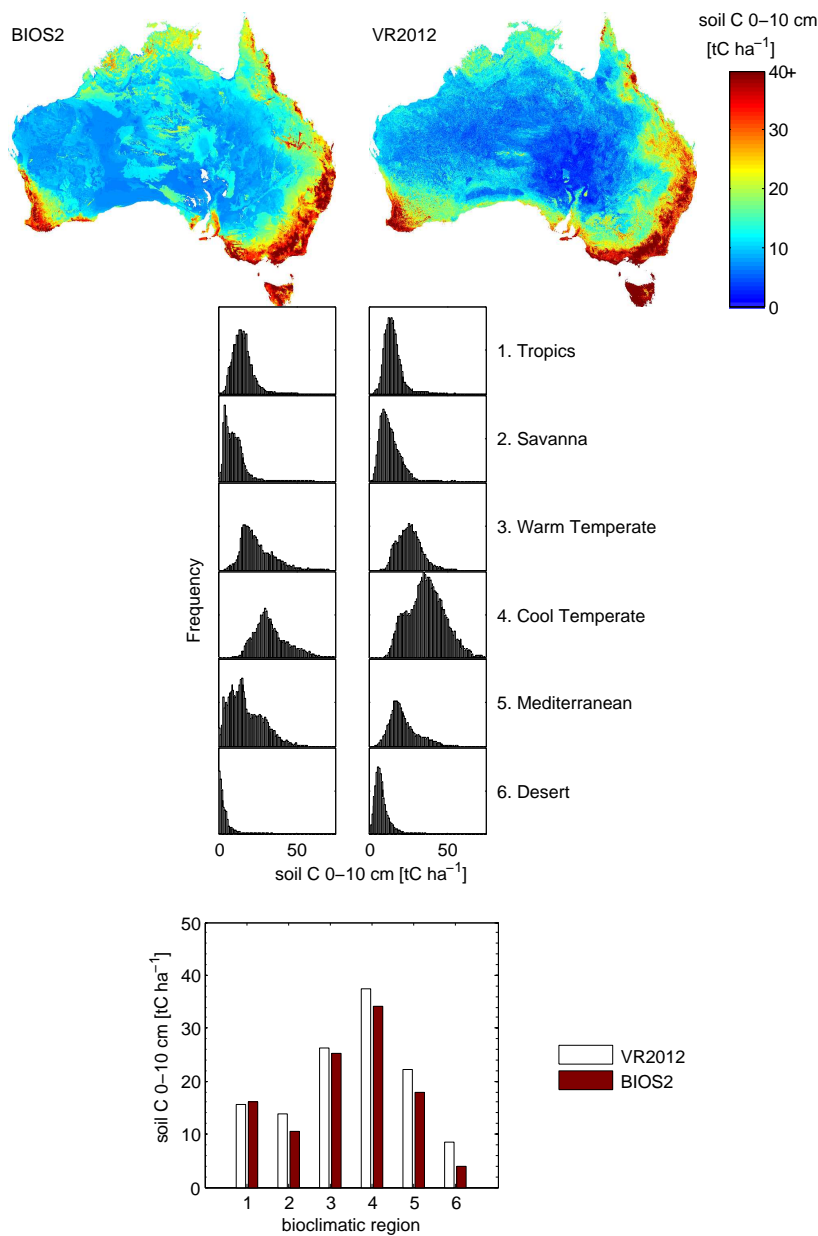

Fig. 10. Comparison of spatial distribution of soil carbon in the top $10 \mathrm{~cm}$ from BIOS2 and VR2012. The frequency histograms for each bioclimatic region are constructed from the mapped values. The barplot compares the BIOS2 and VR2012 means for each region.

\section{Estimates and uncertainties of terms in long-term mean (1990-2011) of the Australian carbon and water budgets}

\subsection{Water balance, NPP and water use efficiency}

Figure 11 shows long-term mean estimates of key quantities in the coupled carbon and water balances, for each bioclimatic region, for the whole continent and for the globe. The global values (excluding Greenland and Antarctica) are taken from previous literature. Global water balance quantities are from the GCM-based assessment of Arora and Boer (2002), while global NPP is from Saugier et al. (2001).

Mean annual precipitation for Australia (with the data used here; see Sect. 2.2) is $493 \mathrm{~mm}$, or $61 \%$ of the global average. Of this, $84 \%$ is evapotranspired (compared with $61 \%$ globally), $14 \%$ is converted to runoff (compared with $36 \%$ globally) and the remainder (2\%) represents a positive change in stored water during the averaging period of 1990

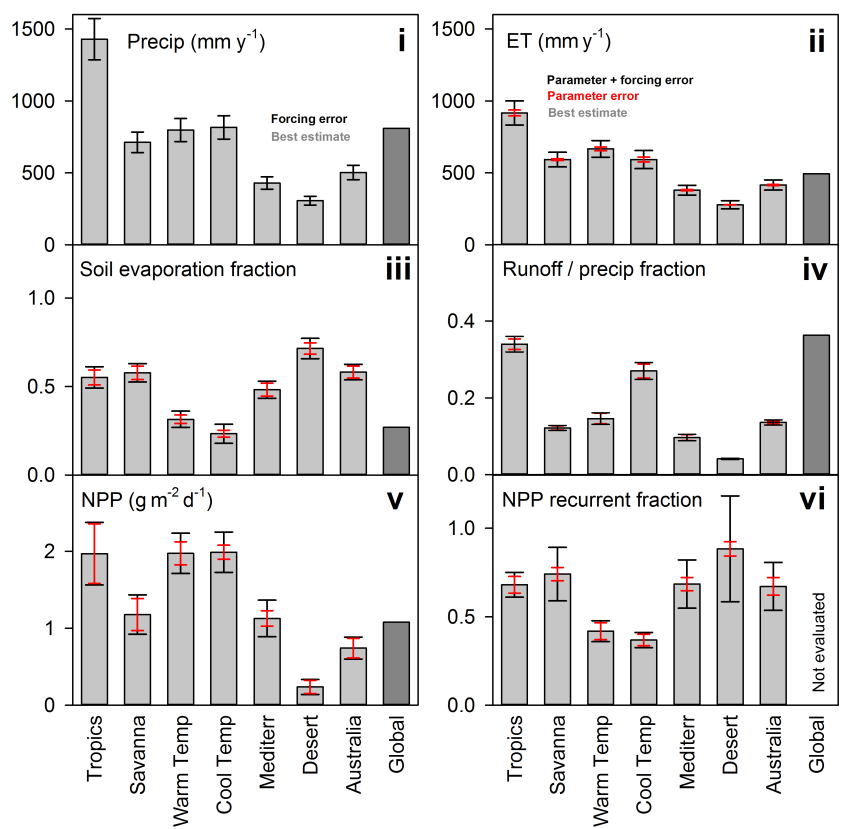

Fig. 11. Long-term mean estimates of key carbon/water cycle variables by bioclimatic region: (i) precipitation; (ii) ET; (iii) soil evaporation as fraction of ET; (iv) runoff as fraction of precipitation; (v) NPP; and (vi) fraction of NPP attributable to recurrent (mainly grassy) vegetation (global estimate unavailable). Error bars represent $1 \sigma$ uncertainties due to parameter (red) and forcing and parameter (black) uncertainties, combined in quadrature.

to 2011. Over half (64\%) of Australian ET is attributable to soil evaporation, which is much higher than the global fraction of $27 \%$ (although this value is highly model-dependent, with values of $28-56 \%$ (Lawrence et al., 2007) and 40-52\% (Sakaguchi and Zeng, 2009) reported in other GCM studies). Continentally, low precipitation and high soil evaporation lead to NPP being lower than the global average $(69 \%$ of the global value) and there is a high proportion (56\%) of NPP attributable to grassy vegetation (including crops and the grassy component of savannas).

Uncertainties in ET are dominated by uncertainty in forcing (particularly precipitation), because ET accounts for $84 \%$ of precipitation. In contrast, uncertainties in the soil evaporation/ET and runoff/precipitation ratios and NPP are dominated by parameter uncertainty. The NPP grass fraction has a large component of forcing uncertainty because the two satellite products (AVHRR and MODIS) give quite different partitioning of $f P A R$ between persistent (woody) and recurrent (grassy) components (see Sect. 6 below).

Figures 12 and 13 show spatial distributions of components of the water balance and NPP respectively. The spatial distributions of components in the water balance and NPP are strongly non-uniform. The spatial pattern of NPP closely resembles that of the transpiration flux. The maps of recurrent (mainly grassy) and persistent (mainly woody) 


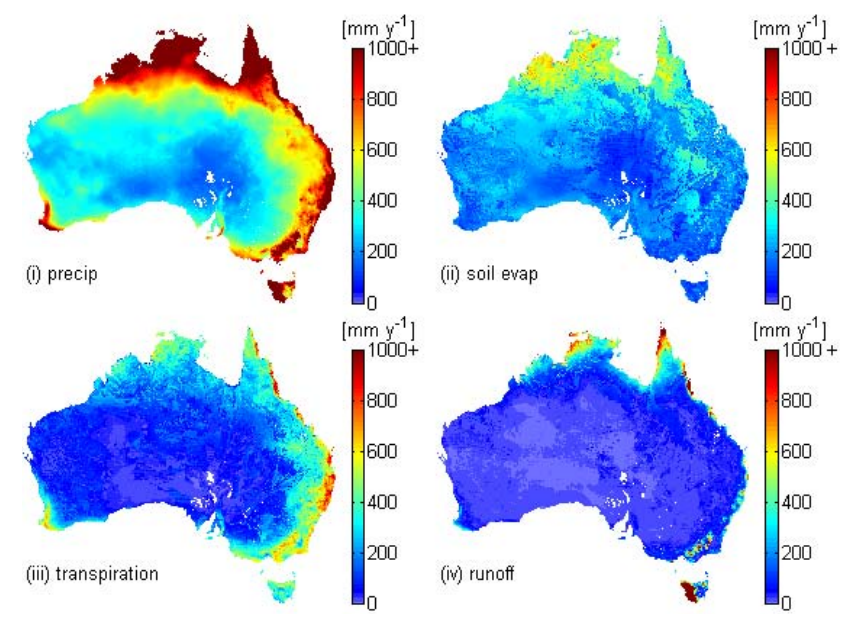

Fig. 12. Maps of terms in long-term (1990-2011) water balance: (i) precipitation; (ii) soil evaporation; (iii) transpiration; and (iv) runoff.

NPP are almost complementary, with the exception of the tropics which supports high woody and grassy productivity.

Figure 14 shows total water use efficiency (GPP/ET), factored into transpiration-use-efficiency (GPP/transpiration and transpiration fraction of ET (transpiration/ET)). Spatial variation in total WUE is controlled largely by the transpiration fraction of ET (because of the importance of soil evaporation), except for agricultural areas of the Mediterranean region, which show high WUE because of high transpirationuse-efficiency. Spatially, transpiration-use-efficiency tends to be anti-correlated with transpiration fraction of ET.

\subsection{Carbon pools and mean residence time of biospheric carbon}

Figure 13 shows the magnitudes of carbon pools and mean residence times (equal to stock/flux at equilibrium (Thompson and Randerson, 1999) of carbon in biomass, soil + litter and the whole biosphere. Despite NPP in the tropics being as high as in the temperate regions (Fig. 11), carbon pools in tropical biomass, litter and soil are much lower (on an unit area basis) and turnover times are faster than in the temperate regions. Biomass in the tropics is lower than in the Temperate zones because the fraction of grassy NPP is higher, while soil and litter carbon pools are smaller because of the positive effects of temperature and moisture on litter and C carbon turnover. The continental biomass estimate from BIOS2 $(25 \pm 9 \mathrm{Pg} \mathrm{C})$ is similar to previous Australian continental estimates of 23.9 Pg C (Berry and Roderick, 2006), 24.0 Pg C (Raupach et al., 2001) and 23.0 Pg C (Barrett, 2002). The mean residence time of continental biospheric $\mathrm{C} 46 \pm 38 \mathrm{yr}$ is lower than the steady state turnover time of $78 \mathrm{yr}$, estimated by Barrett (2001). Relative uncertainties in carbon pools and residence times are much larger than those estimated for key fluxes and flux partitioning (Fig. 11). Forcing uncertainties

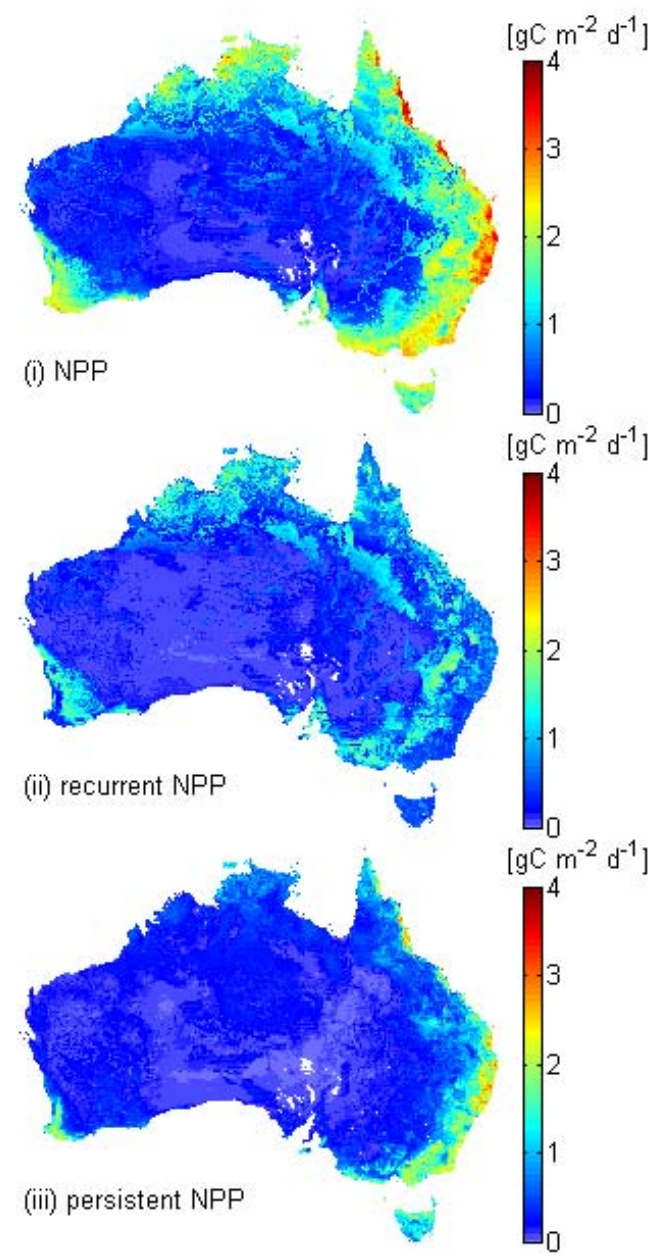

Fig. 13. Maps of terms in long-term (1990-2011) NPP: (i) total NPP; (ii) recurrent (mostly grassy) NPP; and (iii) persistent (mostly woody).

are dominated by contributions from uncertainties in NPP and the fraction of NPP attributable to grassy vegetation, with minor contributions from uncertainties in soil moisture and temperature and model initialisation.

\subsection{Robustness of regional uncertainty estimates on long-term mean observables}

The robustness of $\pm 1-\sigma$ regional uncertainty estimates was confirmed by comparison with model/observation residuals for five observables (ET, litterfall (leaf NPP), above ground biomass, above-ground fine litter carbon and soil carbon density). For each of these, there are sufficient observations in each bioclimatic region to allow assessment of regional bias of BIOS2 predictions relative to observations. Figure 16 shows the $\pm 1-\sigma$ regional uncertainty estimates alongside normalised mean absolute error (NMAE) for each observable $x$ :

$\operatorname{NMAE}_{x}=\overline{x_{\mathrm{BIOS} 2}-x_{\text {obs }}} / \overline{x_{\mathrm{obs}}}$. 


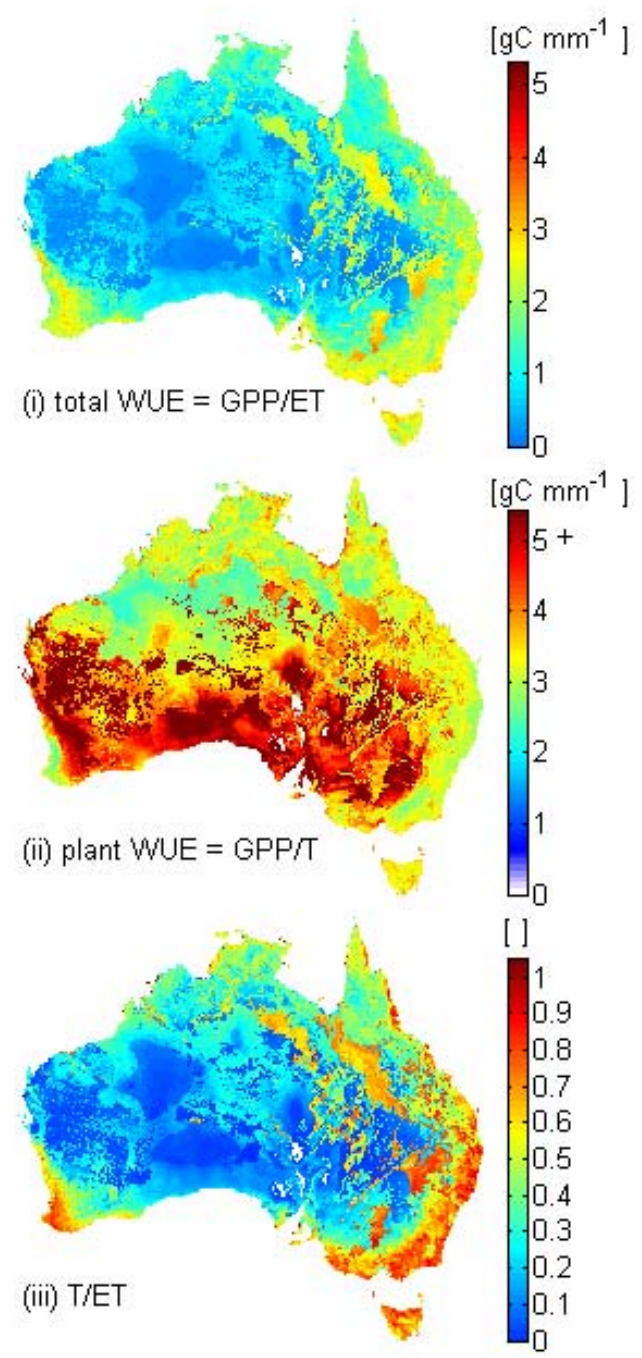

Fig. 14. Maps of long-term (1990-2011) total WUE (i) and its factors: transpiration use efficiency (ii) and fraction of ET which is transpiration (iii).

For each observable, NMAE is the mean bias of the predictions with respect to the observations, normalised by the mean of the observations. NMAE and predicted uncertainties increase in order of ET $(\sim 0.1)$; leaf NPP $(\sim 0.2)$; aboveground biomass $(\sim 0.25)$; soil $\mathrm{C}$ density and fine litter carbon $(\sim 0.5)$. The absolute NMAE was consistently smaller than the $2 \sigma$ regional uncertainty estimates for each observable and mostly smaller than the $1 \sigma$ regional uncertainty estimates. Significant exceptions to the latter are savanna leaf NPP (high model bias); savanna, Cool-Temperate and desert biomass (low model bias), Mediterranean biomass (high model bias). For soil carbon density, BIOS2 showed large negative biases with respect to the VAST soil carbon in the tropics and temperate regions (see also Fig. 9v), but much smaller biases with respect to VR2012. Conversely, in
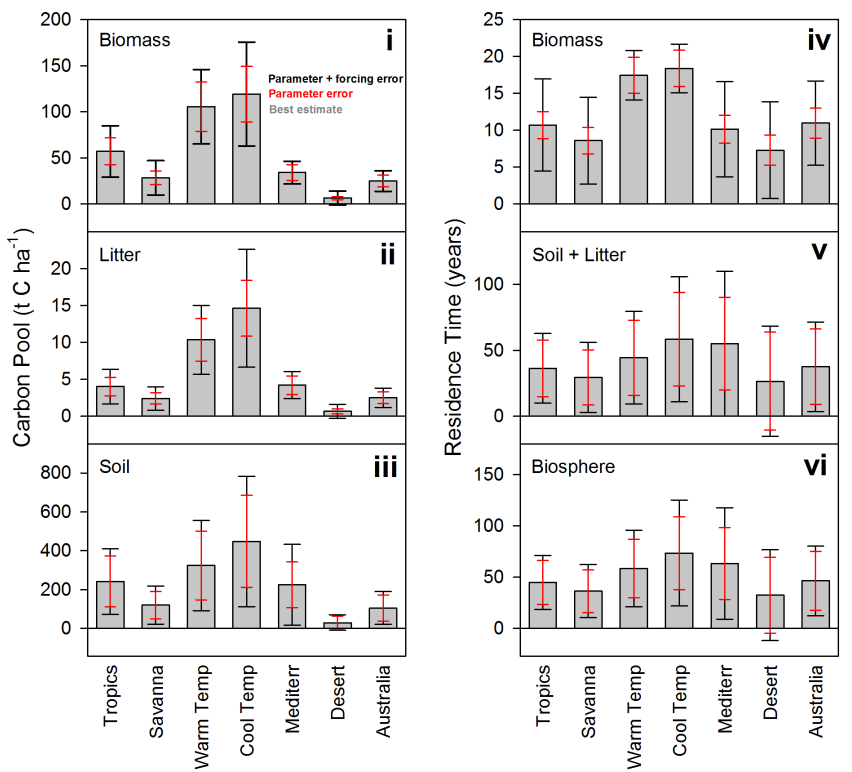

Fig. 15. Carbon pools and turnover times by bioclimatic classification.

the desert, BIOS2 is strongly negatively biased with respect to VR2012, but not with respect to VAST soil carbon.

\subsection{Comparison of BIOS2 long-term NPP and ET with previous continental estimates}

Figure 17 compares BIOS2 estimates of NPP and ET with other continental estimates that were compiled in reviews by Roxburgh et al. (2004) and King et al. (2011). Across all 6 bioclimatic regions, BIOS2 estimates of NPP lie within the range of 12 previous estimates, but none of the 12 estimates lies within $\pm 1-\sigma$ BIOS uncertainty bounds across all regions. Interestingly the lowest two estimates of Australian NPP, BiosEquil (Raupach et al., 2001) and VAST (Barrett, 2002), both used the same litterfall (leaf-NPP) data set for model calibration as was used in this work. This apparent discrepancy can be reconciled by considering the leaf allocation coefficients which were $0.2-0.28$ for BIOS2 (Table A2), but much higher in BiosEquil and Vast (0.6-0.7) (Barrett, 2010).

Multiple model estimates of long-term ET were much more consistent than for NPP. This stems from the ET estimates being largely constrained by precipitation, except for the anomalously low MODIS estimate, which is not.

\section{Interannual variability of flux components of the Australian continental carbon and water budgets}

Figure 18 shows annual time series of key terms in the continental water $(\mathrm{a}-\mathrm{d})$ and carbon $(\mathrm{e}-\mathrm{h})$ budgets. Except for precipitation, there are two time series for each variable, corresponding to results derived using LAI from AVHRR and MODIS FPAR. The $1-\sigma$ uncertainty shading (combined 


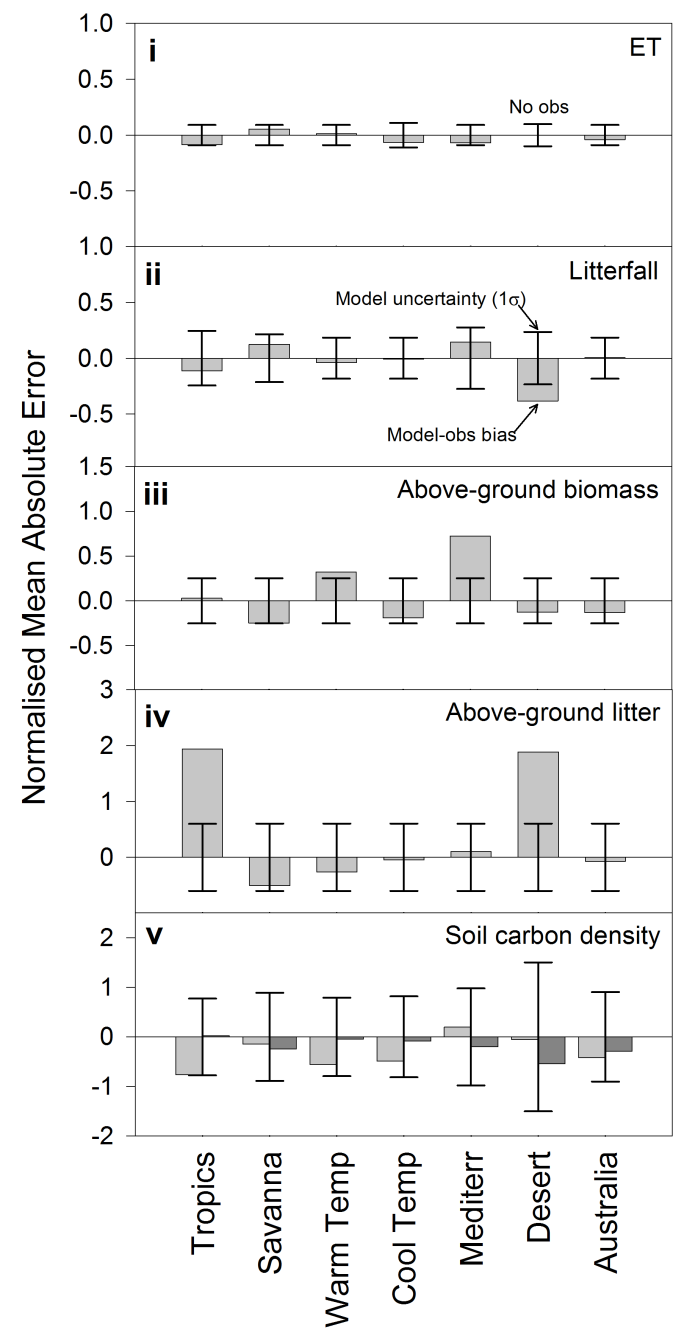

Fig. 16. Normalised mean absolute error (bias) in predictions of long-term (i) catchment-scale ET derived from streamflow; (ii) leaf NPP; (iii) above-ground biomass; (iv) litter carbon; (v) soil carbon density with respect to observations, and corresponding uncertainty estimate in long-term model predictions of observables, aggregated to spatial means for each bioclimatic region and for the whole of Australia.

parameter and forcing errors) is shown for only one of the two time series, but is indicative of the uncertainty for both. Periods of constant LAI (post 2006 for AVHRR and pre 2000 for MODIS) correspond to periods when a monthly climatology was used owing to data being unavailable.

Evapotranspiration (Fig. 18ii) accounts for $84 \%$ of 19902011 mean precipitation and closely tracks its interannual variation, while the annual soil evaporation fraction (Fig. 17iii) remains relatively constant. Large decreases in the soil water store (50-60 mm) in 1994, 2001 and 2002 correspond with low rainfall in these years, while similarly high increases occurred in high rainfall years of 2000 and 2010, but not 2011 because the soil was already very wet from the

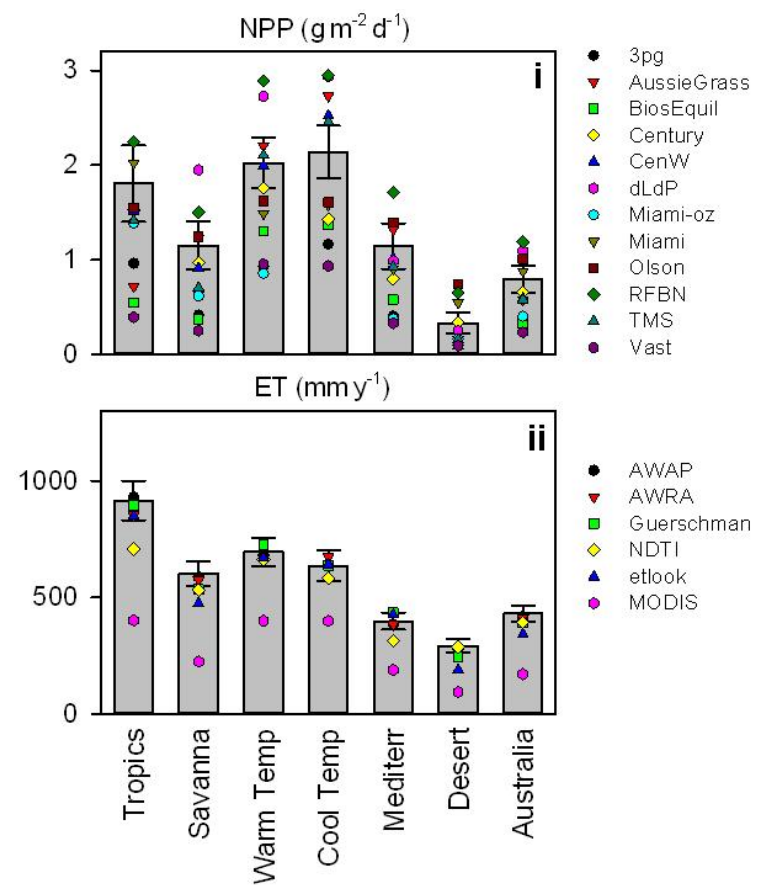

Fig. 17. BIOS2 estimates of long-term NPP and ET by bioclimatic region. Superimposed are multiple model estimates of NPP (Roxburgh et al., 2004) and ET (King et al., 2011).

previous year's soil water increment (Fig. 18iv). At a continental scale, LAI derived from AVHRR fPAR is poorly correlated with rainfall $\left(R^{2}=0.21, n=17\right)$, in contrast to MODIS ( $R^{2}=0.89, n=12$ ) (Fig. $18 \mathrm{v}$ ), and the two remotesensing products lead to fractions of recurrent NPP which differ by $\sim 0.1$ (Fig. 18vii). However, the LAI discrepancy translates to a very small $(<7 \%)$ discrepancy in annual continental NPP during the period of data overlap (2000-2006), and both time series of NPP respond strongly to interannual variation in rainfall, showing major peaks in 2000 and 2011 (Fig. 18vi). NEP also shows high values associated with the high rainfall years of 2000 and 2010 (Fig. 18viii), but unlike NPP, does not continue to increase in 2011, owing to the delayed increase in heterotrophic respiration. 2002 was a year of particularly low NEP, with $2 \mathrm{yr}$ of large decreases in soil moisture (Fig. 18iv) causing a decline in NPP (Fig. 18vi), particularly the grassy fraction (Fig. 18vii). The continental NEP anomaly was attributable largely to interannual variability in savanna and desert NPP. Together, these regions, which account for $78 \%$ of continental surface and $55 \%$ of longterm mean NPP, explain $97 \%$ of the variance in the continental annual NEP and account for $90 \%$ of the 2000 peak; $72 \%$ of the 2002 minimum and $80 \%$ of the 2010 peak.

The IAV of NEP $\left(0.13 \mathrm{PgC} \mathrm{yr}^{-1}(1 \sigma)\right.$ derived using AVHRR) is comparable to Australia's total greenhouse gas (GHG) emissions in 2009-2010 (0.15 $\left.\mathrm{Pg} \mathrm{Ceq} \mathrm{yr}^{-1}\right)$ (DCCEE, 2012). We do not include in this estimate of IAV the impact of disturbance (particularly fire) on the temporal 

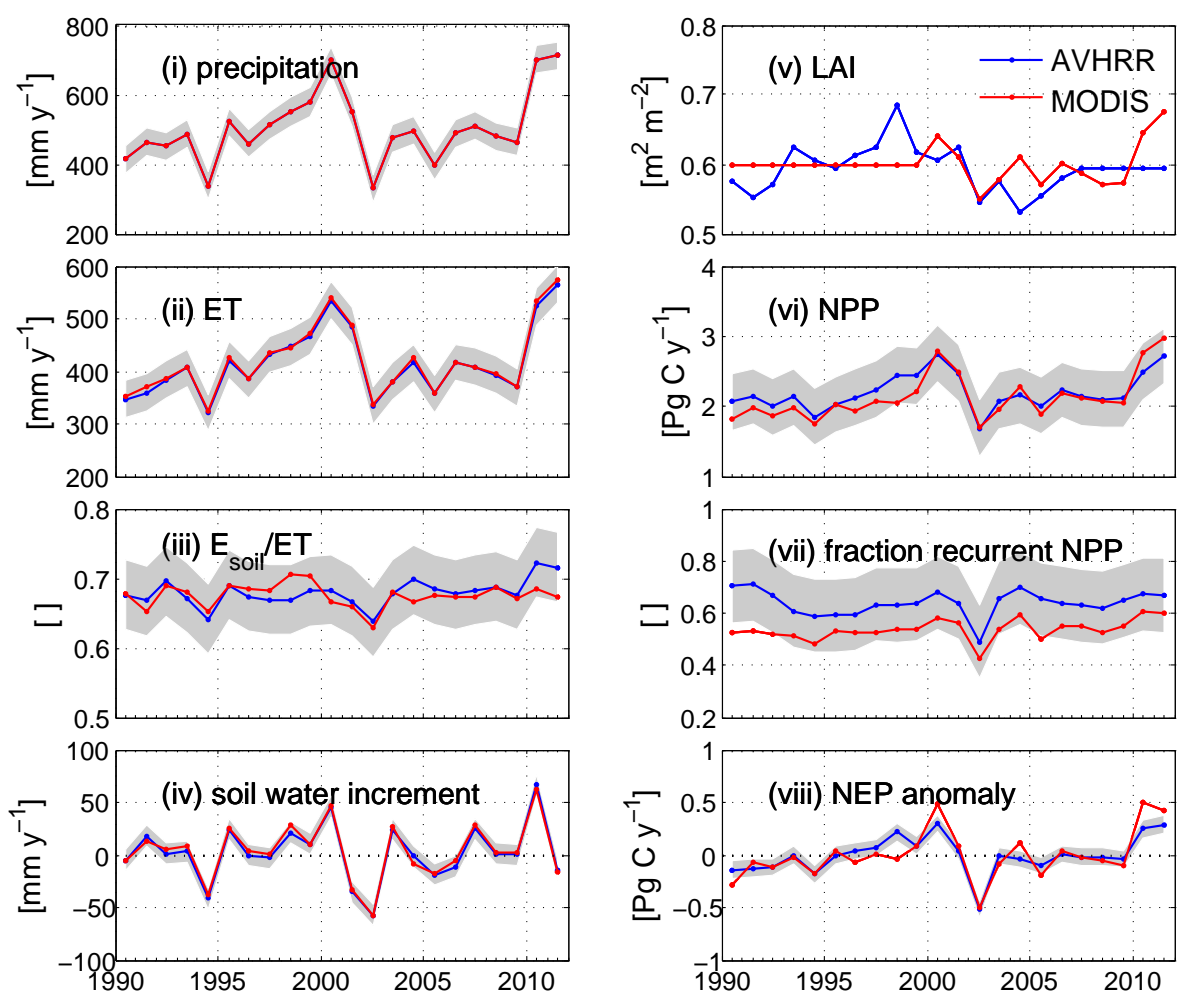

Fig. 18. Annual time series (1990-2011) of continental area-averaged (i) precipitation; (ii) ET; (iii) $E_{\text {soil }} / \mathrm{ET}$; (iv) increment in soil water column; (v) LAI (derived from MODIS and AVHRR fPAR); (vi) NPP; (vii) fraction of NPP from recurrent (mainly grassy) vegetation; and (viii) net ecosystem productivity anomaly (or carbon stock increment relative to mean increment over 1990-2011 period). Shading indicates the 1- $\sigma$ uncertainty arising from parameter and forcing uncertainties. Blue and red lines denote results derived using LAI from AVHRR fPAR and MODIS fPAR, respectively.

variability of the rate constant for biomass decomposition. However we expect the effect to be an increase in IAV approximately equal to the IAV of gross $\mathrm{C}$-emissions from biomass burning, which is relatively small $\left(0.03 \mathrm{Pg} \mathrm{C} \mathrm{yr}^{-1}\right.$ $(1 \sigma))$ (Haverd et al., 2013)

Large swings in continental soil water and carbon storage, as evidenced in Fig. 18(iv) and (viii), have global significance. For example, the $62 \mathrm{~mm}$ continentally averaged increase in soil water in 2010 is equivalent to a sea level change of $1.2 \mathrm{~mm}$ (based on the Australian land area being $2 \%$ of global ocean area). This is a significant fraction $(24 \%)$ of the observed $\sim 5 \mathrm{~mm}$ decline in global sea level in 2010 (Boening et al., 2012) attributed to temporary transfer of large volumes of water from the oceans to the land surfaces. This remarkable replenishment of soil moisture in 2010 resulted in an NEP anomaly of $0.5 \mathrm{Pg} \mathrm{Cyr}^{-1}$, which is significant compared to the mean global terrestrial sink of about 2.4 $\mathrm{Pg} \mathrm{Cyr}^{-1}$ (Canadell et al., 2007; Pan et al., 2011).

\section{Summary and conclusion}

We have quantified key terms in the Australian continental carbon and water balances using a multiple constraints ap- proach. Key results are that over half $(64 \%)$ of ET is attributable to soil evaporation and $67 \%$ of NPP is attributable to recurrent (mainly grassy) vegetation. Spatial variation in total WUE is controlled largely by the transpiration fraction of ET, and temporal variation in net ecosystem productivity is explained largely by variation in precipitation.

Predictions of BIOS2 were evaluated against multiple data sets and regional-scale uncertainty estimates were generally consistent with model/observation biases. A key exception is soil carbon density, where there are large discrepancies between VAST point observations and BIOS2, particularly for the Cool Temperate region, and the tropics, where there is also a large discrepancy between VAST soil carbon density and the VR2012 product.

We explored the uncertainty in Australian continental NPP. While eddy flux measurements provide a significantly tighter constraint on continental NPP than the other data types simultaneous constraint by multiple data types is valuable since this mitigates bias from any single type. The resulting uncertainties in NPP at regional scale are small compared with the range of previous estimates. 


\section{Appendix A}

\section{Modifications of SLI soil scheme for BIOS2}

We modified SLI relative to its original version (Haverd and Cuntz, 2010). We describe below: (A) modified soil water extraction; (B) modified soil surface energy balance computation; (C) a new solution for the coupled heat and moisture equations under freezing conditions. Symbol definitions (Haverd and Cuntz, 2010) are reproduced below for convenience:

\begin{tabular}{|c|c|c|}
\hline$c_{\text {soil }}$ & volumetric heat capacity of soil & $\left(\mathrm{J} \mathrm{m}^{-3} \mathrm{~K}^{-1}\right)$ \\
\hline$c_{\mathrm{W}}$ & $\begin{array}{l}\text { volumetric heat capacity of liquid } \\
\text { water }\end{array}$ & $\left(\mathrm{J} \mathrm{m}^{-3} \mathrm{~K}^{-1}\right)$ \\
\hline$c_{\mathrm{V}}$ & $\begin{array}{l}\text { concentration of water vapour in } \\
\text { soil air spaces }\end{array}$ & $\left(\mathrm{m}^{3} \mathrm{H}_{2} \mathrm{O}_{(\mathrm{l})} \mathrm{m}^{-3}\right.$ (air)) \\
\hline$c_{\mathrm{V}, \text { sat }}$ & $\begin{array}{l}\text { saturated concentration of water } \\
\text { vapour in soil air spaces }\end{array}$ & $\left(\mathrm{m}^{3} \mathrm{H}_{2} \mathrm{O}_{(\mathrm{l})} \mathrm{m}^{-3}\right.$ (air)) \\
\hline$c_{\mathrm{V}, \mathrm{a}}$ & $\begin{array}{l}\text { concentration of atmospheric water } \\
\text { vapour }\end{array}$ & $\left(\mathrm{m}^{3} \mathrm{H}_{2} \mathrm{O}_{(\mathrm{l})} \mathrm{m}^{-3}\right.$ (air)) \\
\hline$c_{\mathrm{V}, \mathrm{s}}$ & $\begin{array}{l}\text { concentration of water vapour at the } \\
\text { soil surface }\end{array}$ & $\left(\mathrm{m}^{3} \mathrm{H}_{2} \mathrm{O}_{(\mathrm{l})} \mathrm{m}^{-3}\right.$ (air)) \\
\hline $\mathrm{d} x$ & soil layer thickness & $(\mathrm{m})$ \\
\hline$D_{\mathrm{v}}$ & $\begin{array}{l}\text { diffusivity of water vapour in the } \\
\text { bulk soil }\end{array}$ & $\left(\mathrm{m}^{2} \mathrm{~s}^{-1}\right)$ \\
\hline$D_{\mathrm{v}, \mathrm{a}}$ & diffusivity of water vapour in air & $\left(\mathrm{m}^{2} \mathrm{~s}^{-1}\right)$ \\
\hline$g$ & gravitational constant & $\left(\mathrm{m} \mathrm{s}^{-2}\right)$ \\
\hline$g$ & Root density distribution function & \\
\hline$G$ & heat flux into surface (soil or litter) & $\left(\mathrm{W} \mathrm{m}^{-2}\right)$ \\
\hline$h$ & pressure head & (m) \\
\hline$h_{\mathrm{e}}$ & pressure head at air entry & (m) \\
\hline$h_{\mathrm{r}}$ & relative humidity & \\
\hline$h_{\mathrm{r}, \mathrm{s}}$ & $\begin{array}{l}\text { relative humidity at air/soil inter- } \\
\text { face }\end{array}$ & \\
\hline$H$ & sensible heat flux at soil surface & $\left(\mathrm{W} \mathrm{m}^{-2}\right)$ \\
\hline$k_{\mathrm{H}}$ & thermal conductivity of bulk soil & $\left(\mathrm{W} \mathrm{m}{ }^{-1} \mathrm{~K}^{-1}\right)$ \\
\hline$k_{\mathrm{E}}$ & latent heat conductivity of bulk soil & $\left(\mathrm{W} \mathrm{m}^{-1} \mathrm{~K}^{-1}\right)$ \\
\hline$K$ & hydraulic conductivity & $\left(\mathrm{m} \mathrm{s}^{-1}\right)$ \\
\hline$K_{\text {sat }}$ & $\begin{array}{l}\text { hydraulic conductivity }\left(\mathrm{m} \mathrm{s}^{-1}\right) \text { of } \\
\text { saturated soil }\end{array}$ & \\
\hline$M_{\mathrm{W}}$ & molar mass of water & $\left(\mathrm{kg} \mathrm{mol}^{-1}\right)$ \\
\hline$M_{\mathrm{i}}$ & molar mass of minor isotopologue & $\left(\mathrm{kg} \mathrm{mol}^{-1}\right)$ \\
\hline$q_{\text {evap }}$ & $\begin{array}{l}\text { evaporative flux from soil or litter } \\
\text { surface to atmosphere }\end{array}$ & $\left(\mathrm{m} \mathrm{s}^{-1}\right)$ \\
\hline$q_{\mathrm{H}}$ & $\begin{array}{l}\text { vertical heat flux }\left(\mathrm{J} \mathrm{m}^{-2} \mathrm{~s}^{-1}\right) \\
\text { within soil column }\end{array}$ & \\
\hline$q_{\mathrm{H}, 0}$ & $\begin{array}{l}\text { vertical heat flux }\left(\mathrm{J} \mathrm{m}^{-2} \mathrm{~s}^{-1}\right) \text { into } \\
\text { top of soil column }\end{array}$ & \\
\hline$q_{1}$ & liquid phase flux of soil moisture & $\left(\mathrm{m} \mathrm{s}^{-1}\right)$ \\
\hline$q_{1}^{\mathrm{i}}$ & $\begin{array}{l}\text { liquid phase flux of minor isotopo- } \\
\text { logue }\end{array}$ & $\left(\mathrm{kg} \mathrm{m}^{-2} \mathrm{~s}^{-1}\right)$ \\
\hline$q_{\mathrm{v}}$ & vapour phase flux of soil moisture & $\left(\mathrm{m} \mathrm{s}^{-1}\right)$ \\
\hline$q_{\mathrm{v}, \mathrm{h}}$ & $\begin{array}{l}\text { component of vapour phase flux of } \\
\text { soil moisture }\left(\mathrm{m} \mathrm{s}^{-1}\right) \text { due to gradi- } \\
\text { ent in }\end{array}$ & $h$ \\
\hline$q_{\mathrm{v}, T}$ & $\begin{array}{l}\text { component of vapour phase flux of } \\
\text { soil moisture }\left(\mathrm{m} \mathrm{s}^{-1}\right) \text { due to gradi- } \\
\text { ent in }\end{array}$ & $T$ \\
\hline$q_{\mathrm{V}}^{\mathrm{i}}$ & $\begin{array}{l}\text { vapour phase flux of minor isotopo- } \\
\text { logue }\end{array}$ & $\left(\mathrm{kg} \mathrm{m}^{-2} \mathrm{~s}^{-1}\right)$ \\
\hline$q_{\mathrm{w}}$ & flux of soil water & $\left(\mathrm{m} \mathrm{s}^{-1}\right)$ \\
\hline
\end{tabular}

\begin{tabular}{|c|c|c|}
\hline$q_{\mathrm{w}, 0}$ & flux of water into top of soil column & $\left(\mathrm{m} \mathrm{s}^{-1}\right)$ \\
\hline$r_{\mathrm{ex}}$ & $\begin{array}{l}\text { sink term accounting for root ex- } \\
\text { traction }\end{array}$ & $\left(\mathrm{s}^{-1}\right)$ \\
\hline$r_{\mathrm{bw}}$ & $\begin{array}{l}\text { boundary-layer resistance to water } \\
\text { vapour transfer }\end{array}$ & $\left(\mathrm{m}^{-1} \mathrm{~s}\right)$ \\
\hline$r_{\mathrm{bH}}$ & $\begin{array}{l}\text { boundary-layer resistance to heat } \\
\text { transfer }\end{array}$ & $\left(\mathrm{m}^{-1} \mathrm{~s}\right)$ \\
\hline$R$ & Gas constant & $\left(\mathrm{J} \mathrm{mol}^{-1} \mathrm{~K}^{-1}\right)$ \\
\hline $\begin{array}{l}R_{\text {net }} \\
s \mathrm{~d} c_{\mathrm{v}, \mathrm{sat}} / \mathrm{d} T\end{array}$ & Net radiation absorbed by soil & $\begin{array}{l}\left(\mathrm{W} \mathrm{m}^{-2} \mathrm{~s}^{-1}\right) \\
\left(\mathrm{m}^{3} \mathrm{H}_{2} \mathrm{O}_{(l)}\right. \\
\left.\mathrm{m}^{-3}(\text { air }) \mathrm{K}^{-1}\right)\end{array}$ \\
\hline$S$ & degree of effective saturation & \\
\hline$T$ & soil temperature & $\left({ }^{\circ} \mathrm{C}\right)$ \\
\hline$T_{\mathrm{a}}$ & air temperature & $\left({ }^{\circ} \mathrm{C}\right)$ \\
\hline$T_{\mathrm{S}}$ & $\begin{array}{l}\text { temperature at air/soil or air/litter } \\
\text { interface }\end{array}$ & $\left({ }^{\circ} \mathrm{C}\right)$ \\
\hline$z$ & vertical co-ordinate & $(\mathrm{m})$ \\
\hline$\alpha$ & root efficiency function & \\
\hline$\gamma$ & $\begin{array}{l}\text { shape parameter in root efficiency } \\
\text { function }\end{array}$ & \\
\hline$\eta$ & $\begin{array}{l}\text { shape parameter for hydraulic con- } \\
\text { ductivity curve }\end{array}$ & \\
\hline$\eta_{\mathrm{E}}$ & $\begin{array}{l}\text { Enhancement factor for transport of } \\
\text { water vapour across a temperature } \\
\text { gradient }\end{array}$ & \\
\hline$\lambda$ & $\begin{array}{l}\text { shape parameter for soil moisture } \\
\text { retention curve }\end{array}$ & \\
\hline$\lambda_{\mathrm{E}}$ & latent heat of vaporisation & $\left(\mathrm{J} \mathrm{kg}^{-1}\right)$ \\
\hline$\lambda_{\mathrm{E}}$ & E latent heat flux at surface & $\left(\mathrm{W} \mathrm{m}^{-2}\right)$ \\
\hline$\varphi_{1}$ & liquid matric flux potential & $\left(\mathrm{m}^{2} \mathrm{~s}^{-1}\right)$ \\
\hline$\rho$ & density of liquid water & $\left(\mathrm{kg} \mathrm{m}^{-3}\right)$ \\
\hline$\rho_{\mathrm{a}}$ & density of air & \\
\hline$\theta_{1}$ & $\begin{array}{l}\text { volumetric liquid soil moisture con- } \\
\text { tent }\end{array}$ & $\left(\mathrm{m}^{3} \mathrm{~m}^{-3}\right)$ \\
\hline$\theta_{\mathrm{r}}$ & $\begin{array}{l}\text { residual volumetric soil moisture } \\
\text { content }\end{array}$ & $\left(\mathrm{m}^{3} \mathrm{~m}^{-3}\right)$ \\
\hline$\theta_{\text {sat }}$ & $\begin{array}{l}\text { saturated volumetric soil moisture } \\
\text { content }\end{array}$ & $\left(\mathrm{m}^{3} \mathrm{~m}^{-3}\right)$ \\
\hline$\tau$ & soil tortuosity & $(<1)$ \\
\hline
\end{tabular}

\section{A1 Sensitivity of stomatal conductance and root-water uptake to soil moisture}

Root-water uptake from level $j$ is modelled as

$r_{\mathrm{ex}, j}=\alpha\left(\theta_{j}\right) g_{j} q_{\mathrm{trans}}$

where $g_{j}$ is the fraction of fine root mass in the $j$-th layer (Eamus et al., 1999), $q_{\text {trans }}$ is the actual transpiration rate and $\alpha(\theta)$ is a root "shut-down" function of Lai and Katul (2000):

$\alpha(\theta)=\left(\frac{\theta-\theta_{\mathrm{w}}}{\theta_{\mathrm{S}}}\right)^{10^{\gamma} /\left(\theta-\theta_{\mathrm{w}}\right)}$

where $\gamma$ is an empirical parameter controlling the rate at which $\alpha(\theta)$ approaches 0 . 
Table A1. Uncertainties in mean (1990-2011) Australian continental carbon and water fluxes, associated with prior parameters and 7 parameter sets obtained by using different observation sets and combinations thereof in the parameter estimation procedure. Uncertainties represent the relative 1- $\sigma$ uncertainty attributable to parameter variance and covariance, calculated using Eq. (3).

\begin{tabular}{lccccc}
\hline & \multicolumn{4}{c}{$\begin{array}{c}\text { Relative uncertainties } \\
\text { to parameter variance and covariance }\end{array}$} \\
\cline { 2 - 6 } Constraint & NPP & $\begin{array}{c}\text { NPP } \\
\text { recurrent } \\
\text { fraction }\end{array}$ & ET & $\begin{array}{c}\text { Soil eva- } \\
\text { poration } \\
\text { fraction } \\
\text { of ET }\end{array}$ & $\begin{array}{c}\text { Runoff } \\
\text { fraction } \\
\text { of } \\
\text { precip }\end{array}$ \\
\hline Prior & & & & 0.17 & 0.11 \\
Eddy fluxes & 0.51 & 0.28 & 0.024 & 0.17 & 0.04 \\
Streamflow & 0.10 & 0.07 & 0.008 & 0.04 & 0.06 \\
Leaf NPP & 0.31 & 0.18 & 0.013 & 0.10 & 0.07 \\
Eddy Fluxes + Leaf NPP & 0.22 & 0.13 & 0.015 & 0.08 & 0.05 \\
Streamflow + Leaf NPP & 0.14 & 0.08 & 0.010 & 0.05 & 0.05 \\
Streamflow + Eddy fluxes & 0.25 & 0.15 & 0.012 & 0.09 & 0.04 \\
Eddy Fluxes + Leaf NPP + Streamflow & 0.12 & 0.07 & 0.008 & 0.04 & 0.05 \\
\hline
\end{tabular}

Table A2. Prior and posterior values of target parameters in CABLE-SLI, and relative sensitivities of continental NPP and soil evaporation to them.

\begin{tabular}{|c|c|c|c|c|c|}
\hline \multirow[t]{2}{*}{$\begin{array}{l}\text { Parameter } \\
\text { (units) }\end{array}$} & \multirow[t]{2}{*}{ Description } & \multirow[t]{2}{*}{$\begin{array}{l}\text { Prior } \\
(1 \sigma)\end{array}$} & \multirow[t]{2}{*}{$\begin{array}{l}\text { Posterior } \\
\qquad(1 \sigma)\end{array}$} & \multicolumn{2}{|c|}{$\begin{array}{c}\text { Relative sensitivity of } \\
\text { continental prediction } \\
\text { to parameter }\end{array}$} \\
\hline & & & & NPP & $E_{\text {soil }}$ \\
\hline Vcmax_g & $\mathrm{V}_{\mathrm{C}, \max }^{25}$ (grassy) & $\begin{array}{r}78.2 \\
(31.1)\end{array}$ & $\begin{array}{r}40.0 \\
(10.9)\end{array}$ & -0.06 & 0.002 \\
\hline $\begin{array}{l}\text { Vcmax_w } \\
\left(\mu \mathrm{mol} \mathrm{m}{ }^{-2} \mathrm{~s}^{-1}\right)\end{array}$ & $\mathrm{V}_{\mathrm{C}, \max }^{25}$ (woody) & $\begin{array}{r}61.4 \\
(27.7)\end{array}$ & $\begin{array}{l}55.5 \\
(9.7)\end{array}$ & 0.12 & -0.02 \\
\hline $\begin{array}{l}\text { RatioVJ } \\
\text { ( ) }\end{array}$ & $\begin{array}{l}\text { Ratio of } \mathrm{V}_{\mathrm{C}, \max }^{25} \text { to the potential rate } \\
\text { of electron transport } \mathrm{J}_{\max }^{25}\end{array}$ & $\begin{array}{r}1.67 \\
(0.50)\end{array}$ & $\begin{array}{r}1.73 \\
(0.21)\end{array}$ & 0.02 & -0.004 \\
\hline $\begin{array}{l}D_{\mathrm{s} 0} \\
(\mathrm{kPa})\end{array}$ & $\begin{array}{l}\text { empirical coefficient reflecting the sensitivity } \\
\text { of stomatal conductance to humidity deficit }\end{array}$ & $\begin{array}{r}1500 \\
(1000)\end{array}$ & $\begin{array}{r}2522 \\
(650)\end{array}$ & -0.27 & 0.149 \\
\hline$a_{1}$ & $\begin{array}{l}\text { Coefficient related to intercellular } \mathrm{CO}_{2} \text { concen- } \\
\text { tration at saturating irradiance by } 1 / a_{1},=1-c_{\mathrm{i}} / c_{\mathrm{S}}\end{array}$ & $\begin{array}{l}10 \\
(5)\end{array}$ & & -0.06 & -0.05 \\
\hline $\begin{array}{l}\text { loggamma_g } \\
(\text { ) }\end{array}$ & $\begin{array}{l}\log _{10}\left(\gamma_{g}\right): \text { sensitivity of stomatal conductance and } \\
\text { root-water uptake to soil moisture (grassy) (Eq. A2) }\end{array}$ & $\begin{array}{l}-2 \\
(1)\end{array}$ & $\begin{array}{l}-1.94 \\
(0.20)\end{array}$ & -0.65 & 0.17 \\
\hline $\begin{array}{l}\text { loggamma_w } \\
\text { ( ) }\end{array}$ & $\log _{10}(\gamma w)$ & $\begin{array}{l}-2 \\
(1)\end{array}$ & $\begin{array}{l}-2.3 \\
(0.6)\end{array}$ & -1.45 & 0.39 \\
\hline $\begin{array}{l}\text { fallocc } \_1 \_g \\
\text { ( ) }\end{array}$ & Leaf carbon allocation coefficient (grassy) & $\begin{array}{r}0.4 \\
(0.2)\end{array}$ & $\begin{array}{r}0.30 \\
(0.06)\end{array}$ & 0 & 0 \\
\hline $\begin{array}{l}\text { fallocc } 1 \text { l_w } \\
\text { ( ) }\end{array}$ & Leaf carbon allocation coefficient (woody) & $\begin{array}{r}0.4 \\
(0.2)\end{array}$ & $\begin{array}{r}0.30 \\
(0.05)\end{array}$ & 0 & 0 \\
\hline
\end{tabular}


Table A3. Prior and posterior values of target parameters in CASA-CNP, and relative sensitivities of continental carbon pools and turnover times to them.

\begin{tabular}{|c|c|c|c|c|c|c|c|c|c|}
\hline \multirow{2}{*}{$\begin{array}{l}\text { Parameter } \\
\text { (units) }\end{array}$} & \multirow[t]{2}{*}{ Description } & \multirow{2}{*}{$\begin{array}{l}\text { Prior } \\
(1 \sigma)\end{array}$} & \multirow{2}{*}{$\begin{array}{r}\text { Posterior } \\
(1 \sigma)\end{array}$} & \multicolumn{6}{|c|}{ Relative Sensitivity } \\
\hline & & & & Biomass C & Litter C & Soil C & $T_{\text {biomass }}$ & $T_{\text {soil+litter }}$ & $T_{\text {biosphere }}$ \\
\hline \multirow[t]{2}{*}{ fallocc_l_g } & Leaf carbon allocation & 0.4 & 0.18 & & & & & & \\
\hline & coefficient (grassy) & $(0.2)$ & $(0.06)$ & 0.023 & 0.010 & 0.001 & -0.466 & 0.001 & 0.005 \\
\hline \multirow[t]{2}{*}{ fallocc_1_w } & Leaf carbon allocation & 0.4 & 0.26 & & & & & & \\
\hline & coefficient (woody) & $(0.2)$ & $(0.02)$ & -0.371 & -0.270 & -0.021 & -0.580 & -0.027 & -0.082 \\
\hline \multirow[t]{2}{*}{ fallocc_w } & Fraction of non-leaf & 0.4 & 0.51 & & & & & & \\
\hline & carbon allocated to wood & $(0.1)$ & $(0.06)$ & 0.949 & 0.604 & 0.044 & 0.762 & 0.056 & 0.200 \\
\hline \multirow[t]{2}{*}{ rsratio_g } & Fine root to shoot & 3.0 & 3.0 & & & & & & \\
\hline & ratio (grassy) & $(0.5)$ & $(0.5)$ & 0.006 & 0.000 & 0.000 & -0.149 & 0.000 & 0.001 \\
\hline \multirow[t]{2}{*}{ rsratio_w } & Fine root to shoot & 0.25 & 0.25 & & & & & & \\
\hline & ratio (woody) & $(0.04)$ & $(0.04)$ & 0.017 & 0.000 & 0.000 & -0.369 & 0.000 & 0.003 \\
\hline age_leaf_g & Leaf turnover time & 0.5 & 0.51 & & & & & & \\
\hline$(\mathrm{yr})$ & grassy (yr) & $(0.1)$ & $(0.1)$ & 0.023 & -0.001 & 0.000 & -0.474 & 0.000 & 0.004 \\
\hline age_leaf_w & Leaf turnover time & 2.0 & 1.9 & & & & & & \\
\hline$(\mathrm{yr})$ & woody (yr) & $(0.5)$ & $(0.5)$ & 0.026 & 0.000 & 0.000 & -0.245 & 0.000 & 0.004 \\
\hline $\begin{array}{l}\text { age_wood } \\
\text { (yr) }\end{array}$ & $\begin{array}{l}\text { Woody biomass turnover } \\
\text { time (yr) }\end{array}$ & - & $\begin{array}{r}58.8 \\
(14.5)\end{array}$ & 0.950 & 0.000 & 0.001 & 0.771 & 0.001 & 0.154 \\
\hline age_clitt1 & Base metabolic litter & 0.04 & 0.04 & & & & & & \\
\hline$(\mathrm{yr})$ & turnover time (yr) & $(0.01)$ & $(0.01)$ & 0.000 & 0.047 & 0.000 & 0.000 & 0.001 & 0.001 \\
\hline age_clitt2 & Base fine structural & - & 0.28 & & & & & & \\
\hline$(\mathrm{yr})$ & litter turnover time (yr) & & $(0.17)$ & 0.000 & 0.252 & 0.000 & 0.000 & 0.005 & 0.004 \\
\hline age_clitt3 & Base coarse woody & 2.0 & 2.0 & & & & & & \\
\hline$(\mathrm{yr})$ & debris turnover time $(\mathrm{yr})$ & $(0.5)$ & $(0.5)$ & 0.000 & 0.698 & 0.000 & 0.000 & 0.015 & 0.012 \\
\hline age_csoill & Base turnover time: fast & 0.3 & 0.3 & & & & & & \\
\hline (yr) & soil C turnover pool (yr) & $(0.08)$ & $(0.08)$ & 0.000 & 0.000 & 0.007 & 0.000 & 0.007 & 0.006 \\
\hline age_csoil2 & Base turnover time: slow & - & 56 & & & & & & \\
\hline$(\mathrm{yr})$ & soil C turnover pool (yr) & & $(32)$ & 0.000 & 0.000 & 0.826 & 0.000 & 0.809 & 0.679 \\
\hline age_csoil3 & Base turnover time: & 220 & 220 & & & & & & \\
\hline$(\mathrm{yr})$ & $\begin{array}{l}\text { passive soil } \mathrm{C} \text { turnover } \\
\text { pool }(\mathrm{yr})\end{array}$ & $(50)$ & $(50)$ & 0.000 & 0.000 & 0.195 & 0.000 & 0.191 & 0.161 \\
\hline soilc0_frac & $\begin{array}{l}\text { Fraction of soil carbon } \\
\text { in top } 15 \mathrm{~cm} \text { of profile }\end{array}$ & $\begin{array}{l}0.14 \\
(0.1)\end{array}$ & $\begin{array}{r}0.14 \\
(0.1)\end{array}$ & 0 & 0 & 0 & 0 & 0 & 0 \\
\hline
\end{tabular}

Modelled stomatal conductance varies linearly with a function of soil moisture, $f_{w, s o i l}$. We redefine this function as

$$
f_{\mathrm{w}, \text { soil }}=\max \left\{\alpha\left(\theta_{j}\right) \delta_{j}, j=1, n\right\} .
$$

where $\delta_{j}=1$ when roots are present and otherwise $\delta_{j}=0$, and $n$ is the total number of soil layers. We multiply the entire stomatal conductance by $f_{\mathrm{w}, \text { soil }}$ (not just the second term as in, Wang et al., 2011, Eq. A18), to avoid the possibility of finite transpiration when there is no extractable water.

\section{A2 Evaluation of soil surface fluxes: improved computation efficiency}

In the original SLI model, coupled energy and moisture conservation equations at the air/soil interface,

$$
\begin{aligned}
& \frac{1}{r_{\mathrm{bw}}}\left[h_{\mathrm{r}, \mathrm{s}}\left(c_{\mathrm{v}, \mathrm{sat}}\left(T_{1}\right)+s\left(T_{1}\right)\left(T_{\mathrm{s}}-T_{1}\right)\right)-c_{\mathrm{v}, \mathrm{a}}\right] \\
& =\frac{D_{\mathrm{v}, 1}}{\mathrm{~d} x_{1} / 2} c_{\mathrm{v}, \mathrm{sat}}\left(T_{1}\right)\left(h_{\mathrm{r}, 1}-h_{\mathrm{r}, \mathrm{s}}\right)+\frac{D_{\mathrm{v}, 1}}{\mathrm{~d} x_{1} / 2} s\left(T_{1}\right) h_{\mathrm{r}, 1}\left(T_{1}-T_{\mathrm{s}}\right) \\
& +\left[\frac{\left(\varphi_{\mathrm{l}}\left(h_{\mathrm{r}, 1}\right)-\varphi_{\mathrm{l}}\left(h_{\mathrm{r}, \mathrm{s}}\right)\right)}{\mathrm{d} x_{1} / 2}-K_{1}\right] \\
& R_{\mathrm{net}}=\frac{\rho_{\mathrm{a}} c_{p}}{r_{\mathrm{bh}}}\left(T_{\mathrm{s}}-T_{\mathrm{a}}\right)+\frac{\rho \lambda_{e} E}{r_{\mathrm{bw}}}-\frac{k_{\mathrm{H}, 1}}{\mathrm{~d} x_{1} / 2}\left(T_{1}-T_{\mathrm{s}}\right) \\
& =\frac{\rho_{\mathrm{a}} c_{p}}{r_{\mathrm{bh}}}\left(T_{\mathrm{s}}-T_{\mathrm{a}}\right)+\frac{\rho \lambda_{e}}{r_{\mathrm{bw}}}\left[h _ { \mathrm { r } , 0 } \left(c_{\mathrm{v}, \mathrm{sat}}\left(T_{1}\right)\right.\right. \\
& \left.\left.+s\left(T_{1}\right)\left(T_{\mathrm{s}}-T_{1}\right)\right)-c_{\mathrm{v}, \mathrm{a}}\right]-\frac{k_{\mathrm{H}, 1}}{\mathrm{~d} x_{1} / 2}\left(T_{1}-T_{\mathrm{s}}\right)
\end{aligned}
$$

were solved numerically for surface temperature $\left(T_{\mathrm{S}}\right)$ and relative humidity $\left(h_{\mathrm{r}, \mathrm{s}}\right)$, and hence the terms in the surface 
Table A4. Root : shoot ratios.

\begin{tabular}{|c|c|c|c|c|c|c|c|}
\hline \multirow{2}{*}{$\begin{array}{l}\text { Original vegetation } \\
\text { category }\end{array}$} & \multirow{2}{*}{$\begin{array}{l}\text { Bioclimatic Region } \\
\text { (BIOS2) }\end{array}$} & \multirow{2}{*}{$\begin{array}{l}\text { Woody/ } \\
\text { grassy }\end{array}$} & \multirow{2}{*}{$\begin{array}{l}\text { Shoot } \\
\text { biomass } \\
\left(\mathrm{tC} \mathrm{ha}^{-1}\right)\end{array}$} & \multicolumn{3}{|c|}{ Root : shoot ratio } & \multirow[t]{2}{*}{$n$} \\
\hline & & & & median & low & high & \\
\hline $\begin{array}{l}\text { Temperate eucalyptus } \\
\text { forest/plantation }\end{array}$ & $\begin{array}{l}\text { Cool temperate/warm } \\
\text { temperate/mediterranean }\end{array}$ & woody & $\begin{array}{l}<50 \\
50-150 \\
>150\end{array}$ & $\begin{array}{l}0.437 \pm 0.048 \\
0.275 \pm 0.06 \\
0.200 \pm 0.03\end{array}$ & $\begin{array}{l}0.286 \\
0.151 \\
0.105\end{array}$ & $\begin{array}{l}0.810 \\
0.811 \\
0.332\end{array}$ & $\begin{array}{l}10 \\
11 \\
6\end{array}$ \\
\hline Savanna & Savanna & woody & & $0.642 \pm 0.111$ & 0.397 & 1.076 & 5 \\
\hline $\begin{array}{l}\text { Tropical/subtropical } \\
\text { moist forest/plantation }\end{array}$ & Tropics & woody & $\begin{array}{l}<125 \\
>125\end{array}$ & $\begin{array}{l}0.205 \pm 0.036 \\
0.235 \pm 0.011\end{array}$ & $\begin{array}{l}0.092 \\
0.220\end{array}$ & $\begin{array}{l}0.253 \\
0.327\end{array}$ & $\begin{array}{l}4 \\
10\end{array}$ \\
\hline $\begin{array}{l}\text { Tropical/subtropical/ } \\
\text { temperate arid } \\
\text { shrubland desert }\end{array}$ & Desert & woody & & 1.063 & 1.063 & 1.063 & 1 \\
\hline $\begin{array}{l}\text { Tropical/subtropical } \\
\text { grassland }\end{array}$ & Tropics/savanna & grassy & & $1.887 \pm 0.304$ & 0.380 & 4.917 & 15 \\
\hline $\begin{array}{l}\text { Temperate grassland } \\
\text { warm temperate/ } \\
\text { Mediterranean/desert }\end{array}$ & Cool temperate/ & grassy & & $4.224 \pm 0.518$ & 1.586 & 9.871 & 16 \\
\hline
\end{tabular}

energy balance. For the current work, we substituted the numerical solution with an accurate analytic approximation for the soil latent heat flux:

$\lambda_{e} E=\min \left[\lambda_{e} E_{\mathrm{pot}},\left(\lambda_{e} E_{\mathrm{vap}, \text { approx }}+\lambda_{e} E_{\text {liq,approx }}\right)\right]$

where $\lambda_{e} E_{\mathrm{pot}}$ is the latent heat flux at $h_{\mathrm{r}, \mathrm{s}}=1$, and $E_{\text {vap,approx }}, E_{\text {liq,approx }}$ are approximations to the vapour and liquid components of the moisture fluxes $\left(\mathrm{kg} \mathrm{m}^{-2} \mathrm{~s}^{-1}\right)$ from within the soil column to the surface:

$$
E_{\mathrm{vap}, \text { approx }}=\left(h_{\mathrm{r}, 1} c_{\mathrm{v}, \mathrm{sat}}\left(T_{1}\right)-c_{\mathrm{v}, \mathrm{a}}\right) /\left(r_{\mathrm{b}, \mathrm{w}}+\left(\mathrm{d} x_{1} / 2\right) / D_{\mathrm{v}, 1}\right)
$$

$E_{\text {liq,approx }}=\rho\left[\frac{\left(\varphi_{1}\left(h_{\mathrm{r}, 1}\right)-\varphi_{\min }\right)}{\mathrm{d} x_{1} / 2}-K_{1}\right]$

where $\varphi_{\min }$ is the matric flux potential corresponding to minimum soil moisture potential, set here to $h_{\min }=-10^{6} \mathrm{~m}$.

The other soil surface energy balance terms (sensible heat and heat conduction into the ground) are then computed using $T_{\mathrm{s}}$, obtained by substituting $\lambda_{e} E$ from Eq. (A6) into Eq. (A5). Equation (A6) replaces the default CABLE latent heat flux, which is formulated as an empirical function of soil moisture in the top soil layer (Wang et al., 2011, Eq. A23).

The effect of litter on the surface energy balance was addressed by adding the litter resistance to soil heat and vapour resistances, $r_{\mathrm{bh}}$ and $r_{\mathrm{bw}}$ (Eqs. A4 and A5). This significantly reduced computation time, relative to solving explicitly for litter temperature and moisture content (as described in Haverd and Cuntz, 2010).

\section{A3 Soil boundary layer resistance}

Resisteances to heat and vapour transfer at the soil surface $r_{\text {bh }}$ and $r_{\text {bw }}$ (Eqs. A4 and A5) are set to the aerodynamic resistance from the soil surface to the air space within the canopy, $r_{\mathrm{g}}$ :

$r_{\mathrm{g}}=\int_{z_{0 \mathrm{~s}}}^{\mathrm{d}} \frac{\mathrm{d} z}{\sigma_{\mathrm{w}}^{2} \tau_{L}}=\frac{1}{u_{*}} \ln \left(\frac{\mathrm{d}}{z_{0 \mathrm{~s}}}\right) \frac{\exp \left(2 c_{\mathrm{s}, \mathrm{w}} L\right)(\mathrm{d} / h)}{a_{3}^{2} c_{T L} f_{\mathrm{sp}}}$

where the vertical velocity standard deviation is formulated as

$\sigma_{\mathrm{w}}=u_{*} a_{3} \exp \left(c_{\mathrm{sw}} L(z / h-1)\right)$

and the Lagrangian time scale as

$T_{L}=f_{\mathrm{sp}}\left(\frac{c_{T L} h}{u_{*}}\right) \frac{z}{\mathrm{~d}}$

where $h$ is canopy height, $u_{*}$ friction velocity; $f_{\text {sp }}$ a canopy sparseness factor; $L$ is leaf area index; $z_{0 \text { s }}$ soil roughness length and d canopy displacement height. The analytical expression for the integral in Eq. (A9) replaces the approximation used by Raupach et al. (1997) and subsequently propagated to CABLE (e.g. Wang et al., 2011 Eq. A14), and results in higher values of $r_{\mathrm{g}}$. 


\section{A4 Freezing/thawing of soil water}

Continuous equations for moisture and energy conservation: The following Eqs. (A12)-(A17) account for the impact of freezing and thawing of soil water on soil energy and water balances, following Fuchs et al. (1978). The rate of ice formation is given by

$\frac{d m_{\mathrm{i}}}{\mathrm{d} t}=-\rho_{l}\left(\frac{\partial q_{1}}{\partial z}-r_{\mathrm{ex}}+\frac{\partial \theta_{1}}{\partial t}\right)$

where $m_{\mathrm{i}}$ is the mass density of ice $\left(\mathrm{kg} \mathrm{m}^{-3}\right.$ soil).

The energy conservation equation is then:

$\frac{c_{\text {soil }} \partial T}{\partial t}-\lambda_{\mathrm{f}} \frac{\mathrm{d} m_{\mathrm{i}}}{\mathrm{d} t}=\frac{\partial q_{\mathrm{H}}}{\partial z}$

where the second term on the LHS is the energy released upon freezing water.

In partially frozen soil, the liquid moisture content is a function of temperature and not total moisture content, allowing us to write:

$\frac{\partial \theta_{1}}{\partial t}=\frac{\partial \theta_{1}}{\partial T_{\text {soil }}} \frac{\partial T_{\text {soil }}}{\partial t}$

Also the flux divergence term in Eq. (A12) can be written as

$$
\frac{\partial q_{1}}{\partial z}=\left(\theta_{\text {sat }}-\theta_{\mathrm{r}}\right) \frac{\partial S}{\partial t}+r_{\mathrm{ex}}
$$

Substituting Eqs. (A12), (A14) and (A15) into Eq. (A13) gives

$\frac{c_{\text {soil }} \partial T}{\partial t}+\lambda_{\mathrm{f}} \rho_{1} \frac{\partial \theta_{1}}{\mathrm{~d} T_{\text {soil }}} \frac{\partial T}{\partial t}=\frac{\partial q_{\mathrm{H}}}{\partial z}$

$+\lambda_{\mathrm{f}} \rho_{\mathrm{l}}\left(\left(\theta_{\mathrm{sat}}-\theta_{\mathrm{r}}\right) \frac{\partial S}{\partial t}\right)$.

The moisture conservation equation is

$\frac{\partial\left(\theta_{\mathrm{l}}+\frac{\rho_{i}}{\rho_{1}} \theta_{i}\right)}{\partial t}=\frac{\partial q_{\mathrm{w}}}{\partial z}-r_{\mathrm{ex}}$.

In discrete form, Eq. (A16) for energy conservation becomes

$$
\frac{\left(c_{\text {soil }, j}+\lambda_{\mathrm{f}} \rho_{\mathrm{l}} \frac{\partial \theta_{\mathrm{l}}}{\partial T}\right) \mathrm{d} x_{j} \Delta T_{j}-\lambda_{\mathrm{f}} \rho_{\mathrm{l}}\left(\theta_{\mathrm{sat}}-\theta_{\mathrm{r}}\right) \mathrm{d} x_{j} \Delta S_{j}}{\Delta t}
$$

$=q_{\mathrm{H}, j}^{\sigma}-q_{\mathrm{H}, j-1}^{\sigma}$.

The latent heat of fusion terms in Eq. (A18) are incorporated into the matrix equations by substituting $c_{\text {soil }, j}$ with an effective heat capacity:

$c_{\mathrm{eff}, j}=c_{\mathrm{soil}, j}+\lambda_{\mathrm{f}} \rho_{1} \frac{\partial \theta_{\mathrm{l}}}{\partial T}$ and modifying the coefficient of $\Delta S_{j}$ :

$$
c_{\mathrm{H}, j}=\left.\frac{\partial q_{\mathrm{H}, j-1}}{\partial S_{j}}\right|^{0}-\left.\frac{\partial q_{\mathrm{H}, j}}{\partial S_{j}}\right|^{0}+\frac{\lambda_{\mathrm{f}} \rho_{\mathrm{l}}\left(\theta_{\mathrm{sat}}-\theta_{\mathrm{r}}\right) \mathrm{d} x_{j}}{\sigma \Delta t} i_{\mathrm{ice}, j}
$$

where $i_{\text {ice, } j}$ equals one where ice is present and zero elsewhere.

In discrete form, Eq. (A17) for moisture conservation becomes

$$
\begin{aligned}
& \frac{\mathrm{d} x_{j}\left(\Delta S_{j}\left(\frac{\rho_{i}}{\rho_{1}} \frac{\partial \theta_{i}}{\partial S}+\frac{\partial \theta_{1}}{\partial S}\right)+\Delta T_{j}\left(\frac{\rho_{i}}{\rho_{1}} \frac{\partial \theta_{i}}{\partial T}+\frac{\partial \theta_{1}}{\partial T}\right)\right)}{\Delta t} \\
& =q_{\mathrm{w}, j-1}^{\sigma}-q_{\mathrm{w}, j}^{\sigma}-r_{\mathrm{ex}, j} .
\end{aligned}
$$

However,

$\frac{\rho_{i}}{\rho_{1}} \frac{\partial \theta_{i}}{\partial S}+\frac{\partial \theta_{1}}{\partial S}=\frac{\partial \theta}{\partial S}$

and

$\frac{\rho_{i}}{\rho_{1}} \frac{\partial \theta_{i}}{\partial T}+\frac{\partial \theta_{1}}{\partial T}=0$.

Therefore, the matrix coefficients for the discretised moisture conservation equations are unchanged from the case when there is no frozen soil water.

Criterion for the presence of ice: Ice is present if the soil temperature is below the freezing point temperature and the total moisture content exceeds the maximum liquid content at that temperature. The freezing point temperature is given by the freezing point depression equation:

$\pi+h=\frac{\lambda_{\mathrm{f}} T_{\text {soil }}}{g\left(T_{\text {soil }}+273.16\right)}$

where $\pi$ is the osmotic potential which depends on solute concentration $c_{\text {sol }}\left(\mathrm{mol} \mathrm{kg}^{-1}\right)$ :

$\pi=\frac{-c_{\mathrm{sol}} R\left(T_{\mathrm{soil}}+273.16\right)}{g}$.

Combining Eqs. (A24) and (A25) gives the maximum liquid moisture content at temperatures below the freezing point:

$$
\begin{aligned}
\theta_{1, \max } & =\theta_{\mathrm{s}}\left(\frac{h}{h_{e}}\right)^{-1 / b} \\
& =\theta_{\mathrm{s}}\left(\frac{\frac{\lambda_{\mathrm{f}} T_{\text {soil }}}{g\left(T_{\text {soil }}+273.16\right)}+\frac{c_{\text {sol }} R\left(T_{\text {soil }}+273.16\right)}{g}}{h_{e}}\right)^{-1 / b} .
\end{aligned}
$$

Convergence of solution for frozen soil layers: The slope of the liquid water content with respect to temperature, $\frac{\partial \theta_{1}}{\partial T}$, and hence the effective heat capacity of partially frozen soil, is strongly temperature dependent, which makes Eq. (A18) for energy conservation non-linear in $\Delta T$. We therefore use the predictor-corrector method, as outlined below, to arrive at a solution for which the value of $\frac{\partial \theta_{1}}{\partial T}$ is consistent with that of the updated soil temperature. 
Predictor step: Updated temperature and moisture variables $\left(T_{\text {pred }}\right.$ and $\left.S_{\text {pred }}\right)$ are calculated using $\left(\frac{\partial \theta_{1}}{\partial T}\right)_{\text {old }}$, which is set initially to its value at time $t-\mathrm{d} t$. A new freezing point temperature is calculated at the updated moisture content, and a predicted value of $\frac{\partial \theta_{1}}{\partial T}$ is calculated as

$$
\left(\frac{\partial \theta_{1}}{\partial T}\right)_{\text {pred }}=\frac{\theta_{1}\left(\min \left[T_{\text {pred }}, T_{\text {frz }}\right], S_{\text {pred }}\right)-\theta_{1}\left(T_{t-\mathrm{d} t}, S_{t-\mathrm{d} t}\right)}{\min \left[T_{\mathrm{pred}}, T_{\mathrm{frz}}\right]-T_{t-\mathrm{d} t}}
$$

Corrector step: The corrected value of $\frac{\partial \theta_{1}}{\partial T}$ is then calculated as

$$
\left(\frac{\partial \theta_{1}}{\partial T}\right)_{\text {corr }}=0.5\left(\left(\frac{\partial \theta_{1}}{\partial T}\right)_{\text {old }}+\left(\frac{\partial \theta_{1}}{\partial T}\right)_{\text {pred }}\right),
$$

and $\left(\frac{\partial \theta_{1}}{\partial T}\right)_{\text {old }}$ is reset to $\left(\frac{\partial \theta_{1}}{\partial T}\right)_{\text {corr }}$. The predictor and corrector steps are iterated until convergence.

Onset of freezing: After updating soil temperature and moisture, we check for the onset of freezing and thawing. First, we evaluate the freezing point temperature at the new moisture content:

$T_{\mathrm{frz}}\left(S, h_{e}, b, c_{\mathrm{sol}}\right)=$

$\frac{g h_{e}-S^{b}\left(\lambda_{\mathrm{f}}+2 c_{\mathrm{sol}} R T_{\mathrm{K}}\right)+\sqrt{\left(g h_{e}\right)^{2}-2 g h_{e} \lambda_{\mathrm{f}} S^{b}+\lambda_{\mathrm{f}} S^{2 \mathrm{~b}}\left(\lambda_{\mathrm{f}}+4 c_{\mathrm{sol}} R T_{\mathrm{K}}\right)}}{2 c_{\mathrm{sol}} R S^{b}}$

or, in the absence of solute,

$T_{\mathrm{frz}}\left(S, h_{e}, b\right)=\frac{g h_{e} T_{\mathrm{K}}}{\lambda_{\mathrm{f}} S^{b}-g h_{e}}$.

The conditions for the onset of freezing are (i) $i_{\text {ice }}=0$; (ii) $T_{\text {uncorr }}<T_{\text {frz }}$, where $T_{\text {uncorr }}$ is the updated temperature, $T_{t-\mathrm{d} t}+\Delta T$, which does not account for the latent heat release upon freezing and therefore underestimates the updated temperature.

The change in energy storage needs to be repartitioned into sensible and latent heat components. The uncorrected and corrected changes in energy storage are formulated as

$$
\Delta J_{\text {uncorr }}=c_{\text {soil }}\left(T_{\text {uncorr }}-T_{t-\mathrm{d} t}\right) \mathrm{d} x
$$

and

$$
\begin{aligned}
\Delta J_{\text {corr }} & =\mathrm{d} x \rho_{1} \lambda_{\mathrm{f}}\left(\frac{\partial \theta_{1}}{\partial T_{\text {soil }}}\left(T_{\text {corr }}-T_{\text {frz }}\right)\right) \\
& +c_{\text {soil }} \mathrm{d} x\left(T_{\text {frz }}-T_{t-\mathrm{d} t}\right)+c_{\text {soil }} \mathrm{d} x\left(T_{\text {corr }}-T_{\text {frz }}\right) .
\end{aligned}
$$

Here $\frac{\partial \theta_{1}}{\partial T_{\text {soil }}}$ is calculated at $T_{\text {soil }}=T_{\text {frz }}$, and defined using $\frac{\partial \theta_{1}}{\partial h}$ :

$$
\frac{\partial \theta_{1}}{\partial T_{\text {soil }}}=\frac{\partial \theta_{1}}{\partial h} \frac{\mathrm{d} h}{\mathrm{~d} T_{\text {soil }}}=\frac{\partial \theta_{\mathrm{l}}}{\partial h}\left(\frac{\lambda_{\mathrm{f}}}{g T_{\mathrm{K}}}-\frac{\lambda_{\mathrm{f}} T_{\text {soil }}}{g T_{\mathrm{K}}^{2}}+\frac{c_{\text {sol }} R}{g}\right)
$$

where

$$
\frac{\partial \theta_{1}}{\partial h}=-\frac{\theta}{b h}
$$

(note here that at the freezing point, $\theta_{1}=\theta$ and $\frac{\partial \theta_{1}}{\partial h}=\frac{\partial \theta}{\partial h}$ ).

In order to maintain conservation of energy, we equate the RHS of Eq. (A32) with that of Eq. (A31), leading to the following expression for the (latent-heat) corrected temperature:

$$
T_{\text {corr }}=\frac{c_{\text {soil }} T_{\text {uncorr }}+\rho_{1} \lambda_{\mathrm{f}} \frac{\partial \theta_{1}}{\partial T_{\text {soil }}} T_{\text {frz }}}{c_{\text {soil }}+\rho_{1} \lambda_{\mathrm{f}} \frac{\partial \theta_{1}}{\partial T_{\text {soil }}}} .
$$

The change in ice content is then:

$\Delta J_{\text {ice }}=\mathrm{d} x\left(\frac{\partial \theta_{1}}{\partial T_{\text {soil }}}\left(T_{\text {frz }}-T_{\text {corr }}\right)\right)$.

We ensure numerical consistency by checking that the change in ice storage as evaluated by Eq. (A36) agrees with that obtained by Eq. (A26), i.e.:

$$
\Delta J_{\text {ice }}=\mathrm{d} x\left(\theta_{\text {l. max }}\left(T_{\text {corr }}\right)-\theta_{\text {l. } \max }\left(T_{t-\mathrm{d} t}\right)\right)
$$

Onset of thawing: The conditions for the onset of freezing are (i) $i_{\text {ice }}=1$; (ii) $T_{\text {uncorr }}>T_{\text {frz }}$. Again, we equate expressions for the uncorrected and corrected formulations for the change in energy storage:

$$
\begin{aligned}
\Delta J_{\text {uncorr }} & =\mathrm{d} x \rho_{\mathrm{l}} \lambda_{\mathrm{f}}\left(\frac{\partial \theta_{\mathrm{l}}}{\partial T_{\text {soil }}}\left(T_{\text {uncorr }}-T_{t-\mathrm{d} t}\right)-\left(\theta_{\mathrm{s}}-\theta_{\mathrm{r}}\right) \Delta S\right)( \\
& +c_{\mathrm{S}}\left(T_{\text {uncorr }}-T_{t-\mathrm{d} t}\right) \mathrm{d} x_{j} \\
\Delta J_{\text {corr }}= & \mathrm{d} x \rho_{1} \lambda_{\mathrm{f}}\left(\frac{\delta \theta_{1}}{\delta T_{\text {soil }}}\left(T_{\text {frz }} T_{t-\mathrm{d} t}\right)-\left(\theta_{\mathrm{s}}-\theta_{\mathrm{r}}\right) \Delta S\right) \\
& +c_{\mathrm{S}}\left(T_{\text {frz }}-T_{t-\mathrm{d} t}\right) \mathrm{d} x+c_{\mathrm{S}}\left(T_{\text {corr }}-T_{\text {frz }}\right) \mathrm{d} x
\end{aligned}
$$

leading to

$T_{\text {corr }}=T_{\text {uncorr }}+\frac{\rho_{1} \lambda_{\mathrm{f}} \frac{\delta \theta_{1}}{\delta T}\left(T_{\text {uncorr }}-T_{\text {frz }}\right)}{c_{\mathrm{s}}}$.

\section{Appendix B}

\section{CABLE-SLI and CASA-CNP parameter values}

\section{B1 CABLE-SLI}

Prior and posterior values of target parameters for CABLESLI are listed in Table A1. Prior parameters for CABLESLI were based on literature values as follows: Prior values of maximum photosynthetic capacity (at $25^{\circ} \mathrm{C}$ ) were taken from Kattge et al. (2009), who recently assimilated 723 observations of carboxylation capacity into the Farquhar model for C3 photosynthesis (Farquhar et al., 1980) (also 
used in CABLE) to estimate $\mathrm{V}_{\mathrm{C}, \max }^{25}$ for several plant functional types (PFTs). We adopt values for temperate broadleaved evergreen trees and C3 herbaceous PFTs as prior values for woody and grassy vegetation, respectively, noting that the value for the Evergreen shrubs PFT is very close to the value for temperate broad-leaved evergreen trees. While the temperature dependence of photosynthesis is distinct for $\mathrm{C} 3$ and $\mathrm{C} 4$ grasses, $\mathrm{V}_{\mathrm{C}, \max }^{25}$ for $\mathrm{C} 4$ grasses is fixed at the $\mathrm{C} 3$ value. Ratio of $\mathrm{V}_{\max }^{25}$ to the potential rate of electron transport $\mathrm{J}_{\max }^{25}$ is based on the review of photosynthetic parameters by Medlyn et al. (2002). The prior value of $D_{\mathrm{s} 0}$ (an empirical parameter relating stomatal conductance to humidity deficit) is taken from Leuning et al. (1995), and is highly uncertain. Sensitivity of stomatal conductance and root-water uptake to soil moisture is specified empirically using the $\gamma$ parameter (Eq. A2), for which woody and grassy vegetation may have different values. We use a prior value from (Lai and Katul, 2000) with a large prior standard deviation because it is a purely empirical parameter and its use is not identical to that in the original reference. Maximum rooting depths were fixed at $0.5 \mathrm{~m}$ for grassy vegetation and $5.0 \mathrm{~m}$ for woody vegetation. While this is clearly an over-simplification, it is expected that the $\gamma$ parameter is so highly correlated with maximum rooting depth that optimisation of rooting depth parameters is redundant.

The NPP to GPP ratio, and leaf carbon allocation coefficients were required to convert CABLE-SLI GPP to leafNPP for comparison with observations. The ratio of NPP to GPP was assumed fixed, with values of $0.46+/ 0.14(1 \sigma$, $n=60$ ) for woody vegetation (DeLucia et al., 2007), and $0.63+/ 0.05$ ( 1 s.d., $n=5$ ) for herbaceous vegetation (Gifford, 2003; Van Oijen et al., 2010). The former is in good agreement with Gifford's earlier result of $0.47+/ 0.05(1 \sigma$, $n=21$ ) (Gifford, 2003). Our prior estimates of leaf carbon allocation coefficients are based on the analysis of Scurlock et al. (2002) (aboveground NPP: total NPP for herbaceous vegetation ranging between 0.25 and 0.7 ), and S. H. Roxburgh (personal communication, 2012), who estimate values of $0.3-0.6$ for leaf carbon allocation in woody vegetation.

\section{B2 CASA-CNP}

Prior parameter estimates for CASA-CNP were quite uncertain, largely because many are constructs of the model and do not relate directly to observables. For example, the soil C pools are arbitrarily partitioned between fast turnover, slow turnover and passive pools, and the base turnover time is converted to the actual turnover time by multiplication with functions of soil temperature and moisture. Thus prior values for the base turnover times of the soil and litter pools can only be estimated from previous modelling studies in which the same (or similar) carbon cycle model has been applied. In the absence of additional data, we adopted prior parameter values from the default parameter file. Exceptions were fine-root-to-shoot ratios in woody and grassy vegeta- tion. These were used to calculate fine root turnover times. The root shoot ratio is highly variable and tends to increase with aridity and sparseness of vegetation. For woody vegetation, the ratio of leaf biomass to fine-root biomass was taken from (Eamus et al., 2002 and references therein), while grassy root-to-shoot ratios were taken from (Mokany et al., 2006). Root shoot ratios for woody vegetation, also from (Mokany et al., 2006) were used to convert modelled woody biomass above-ground biomass for comparison with observations (Table A4). Similarly, an estimate of the fraction of soil $\mathrm{C}$ in the top $15 \mathrm{~cm}$ of soil was required to converted modelled total soil $\mathrm{C}$ to the observable quantity. The prior value is taken from Jobaggy and Jackson (2000) and the large uncertainty due to significant variations across biomes.

\section{Appendix C}

\section{Forcing data}

\section{C1 Meteorology}

BIOS2 is forced by daily gridded rainfall, temperature, vapour pressure and solar irradiance surfaces at $0.05^{\circ}$ spatial resolution from the Bureau of Meteorology's Australian Water Availability Project data set (BoM AWAP) (Grant et al., 2008; Jones et al., 2009). The data were downloaded in March 2012. Changes made to fill temporal and spatial gaps in the rainfall and solar irradiance series for the period 1 January 1950 to 31 December 2011 are as follows:

Rainfall: The daily rainfall used here is the BoM AWAP "recalibrated" product (Jones et al., 2009). Recalibration is a rescaling of the original daily surfaces to ensure that their sums match exactly the monthly surfaces created by reanalysis using monthly gauge totals. The discrepancy arises primarily from the different length scales used to interpolate daily $(80 \mathrm{~km})$ and monthly $(250 \mathrm{~km})$ rainfall observations. Averaged over time (e.g. $30 \mathrm{yr}$ ) the rescaling over most of the continent involves adjustments of up to $\pm 10 \%$ in rainfall totals. Due to the shorter length scale, daily surfaces include areas of missing data in the sparsely-gauged central and western deserts. To facilitate modelling in these areas, locations with one or more missing data values during a month were assigned the average daily rainfall calculated from the corresponding gap-free monthly reanalysis.

Solar Radiation: The BoM AWAP solar irradiance product begins on 1 January 1990 and is derived from GMS and GOES-9 satellite imagery processed by the Bureau of Meteorology (Grant et al., 2008). The daily series includes missing values and days. The monthly series is adjusted to account for the effects of missing days. Missing values in the daily series were filled using a monthly climatology (1990-2011), created from the monthly series. This climatology was also used to create a synthetic daily series to fill the period 1950 
to 1989 , consisting of the same gridded surface for all days in the corresponding months.

\section{C2 Weather Generator}

CABLE operates at subdiurnal time steps. Therefore, meteorological and radiative forcings were downscaled from daily to hourly time steps (on the half-hour) using the following algorithms.

Daily precipitation observations refer to the amount accumulated in the $24 \mathrm{~h}$ prior to 09:00 on the day in question. The following day's total was distributed evenly over three hours: 15:00-16:00; 16:00-17:00 and 18:00-19:00. This fixed distribution was chosen in preference to a uniform distribution because the latter resulted in a high number of modelled wet canopy hours, leading to unrealistic suppression of carbon uptake, particularly in the tropical wet season.

Hourly air temperatures are calculated according to the temperature model of Cesaraccio et al. (2001), using daily minimum and maximum temperatures and calculated times for local sunrise and sunset. Daylight hours are modelled as separate sine-wave functions either side of the time of maximum temperature, with a square root temperature decrease at night. Hours between 00:00 and sunrise are modelled using the previous day's information.

Between sunrise and sunset, daily total solar irradiance is converted to hourly instantaneous downward solar irradiance according to Paltridge and Platt (1976, Eq. 3.4).

Hourly longwave radiation is calculated as a function of the Cesaraccio et al. (2001) temperatures using the formulation of Brutsaert (1975). Where the result is outside the range 100 to $500 \mathrm{~W} \mathrm{~m}^{-2}$, longwave radiation is recalculated using Swinbank (1963). A cloud adjustment factor (G. Abramowitz, personal communication, 2010) is applied to the Brutsaert formulation.

Hourly vapour pressure on consecutive days is calculated from linear interpolation between instantaneous measurements of vapour pressure at 09:00 and 15:00 local time.
Atmospheric pressure is given a prescribed value for all hours of $1000 \mathrm{mb}$. Wind speeds are also prescribed with separate values for daylight $\left(3 \mathrm{~m} \mathrm{~s}^{-1}\right)$ and night hours $\left(1 \mathrm{~m} \mathrm{~s}^{-1}\right)$.

\section{C3 Soil Information}

Spatially varying soil properties used by BIOS2 are bulk density, clay and silt fractions, saturated hydraulic conductivity, suction at saturation, field capacity, wilting point, and saturated volumetric water content. Ten soil layers are defined in the model with thicknesses in metres of (top to bottom): $0.022,0.058,0.07,0.15,0.30,0.30,0.30,1.20,3.0$, and 4.5.

Soil information is taken from the McKenzie and Hook (1992) and McKenzie et al. (2000) interpretations of the 725 principal profile forms (soil types) mapped in the Digital Atlas of Australian Soils (DAAS) (Northcote et al., 1960; Northcote et al., 1975). Soil properties are estimated using a simple two-layer model of the soil consisting of an A and B horizon. For each layer, the horizon thickness, texture, clay content, bulk density, grade of pedality and saturated hydraulic conductivity are given. Available water capacities for each layer are determined from the estimates of thickness, texture, bulk density and pedality (McKenzie et al., 2000). Pedotransfer functions (McKenzie and Hook, 1992; McKenzie et al., 2000) are expressed as classes with median, 5th and 95 th percentile values.

The soil information was matched to the model requirements as follows: To match the spatial grid of the forcing meteorology, the $1: 2000000$ scale DAAS was rasterised, assigning the dominant soil type within each $0.05^{\circ}$ grid cell. This reduced the number of discrete soil types across the continent from 725 to 300 . Areas with missing data or classified as having no soil (inland water, salt lakes, salt pans, some coastal features) were not modelled. For each of the remaining 300 soil types, the class medians from the pedotransfer functions were used to create maps of the required physical soil properties. 
Appendix D

Parameter error correlation matrices

Table D1. CABLE-SLI.

\begin{tabular}{lrrrrrrrr}
\hline & alloclg & alloclw & ratioVJ & vcmax_g & loggamma_g & vcmax_w & loggamma_w & ds0 \\
\hline alloclg & 1.000 & $-\mathbf{0 . 5 6 8}$ & -0.013 & -0.175 & -0.046 & 0.047 & -0.001 & 0.055 \\
alloclw & & 1.000 & -0.030 & -0.054 & -0.059 & $-\mathbf{0 . 1 2 1}$ & -0.002 & 0.074 \\
ratioVJ & & & 1.000 & 0.013 & -0.025 & $-\mathbf{0 . 7 2 2}$ & 0.026 & -0.061 \\
vcmax_g & & & & 1.000 & $\mathbf{0 . 6 1 1}$ & $-\mathbf{0 . 2 2 0}$ & $-\mathbf{0 . 2 0 1}$ & $-\mathbf{0 . 3 3 0}$ \\
loggamma_g & & & & & 1.000 & 0.018 & $-\mathbf{0 . 1 9 0}$ & $\mathbf{0 . 1 7 8}$ \\
vcmax_w & & & & & & 1.000 & 0.024 & 0.034 \\
loggamma_w & & & & & & & 1.000 & $\mathbf{0 . 2 0 1}$ \\
ds0 & & & & & & & & \\
\hline
\end{tabular}

Table C1. CASA-CNP.

\begin{tabular}{|c|c|c|c|c|c|c|c|c|c|c|c|c|c|c|c|}
\hline & $\begin{array}{r}\text { soilc0 } \\
\text { frac }\end{array}$ & $\begin{array}{r}\text { age } \\
\text { _leaf_g }\end{array}$ & $\begin{array}{r}\text { age } \\
\text { _leaf_w }\end{array}$ & $\begin{array}{r}\text { age } \\
\text { _wood }\end{array}$ & $\begin{array}{r}\text { age } \\
\text { clitt1 }\end{array}$ & $\begin{array}{r}\text { age } \\
\text { clitt2 }\end{array}$ & $\begin{array}{r}\text { age } \\
\text { clitt3 }\end{array}$ & $\begin{array}{r}\text { age } \\
\text { _csoil1 }\end{array}$ & $\begin{array}{r}\text { age } \\
\text { _csoil2 }\end{array}$ & $\begin{array}{r}\text { age } \\
\text { _csoil3 }\end{array}$ & $\begin{array}{r}\text { fallocc } \\
-W\end{array}$ & $\begin{array}{r}\text { fallocc } \\
\quad l_{-} g\end{array}$ & $\begin{array}{r}\text { falloce } \\
\text { _l_W }\end{array}$ & $\begin{array}{r}\text { rsratio } \\
-\mathrm{W}\end{array}$ & $\begin{array}{r}\text { rsratio } \\
-\mathrm{g}\end{array}$ \\
\hline soilc0_frac & 1.000 & 0.000 & 0.000 & -0.001 & 0.000 & 0.000 & 0.000 & 0.000 & -0.984 & -0.001 & 0.001 & 0.000 & 0.000 & 0.000 & 0.000 \\
\hline age_leaf_g & & 1.000 & 0.007 & 0.000 & 0.000 & 0.020 & 0.000 & 0.000 & 0.000 & 0.000 & 0.000 & -0.006 & 0.005 & 0.000 & 0.000 \\
\hline ge_leaf_w & & & 1.000 & -0.013 & 0.000 & 0.981 & 0.000 & 0.000 & 0.000 & 0.000 & 0.000 & -0.016 & 0.024 & 0.000 & 0.000 \\
\hline age_wood & & & & 1.000 & 0.000 & -0.001 & 0.000 & 0.000 & 0.021 & 0.000 & -0.983 & -0.064 & 0.086 & 0.000 & 0.000 \\
\hline age_clitt1 & & & & & 1.000 & 0.000 & 0.000 & 0.000 & 0.000 & 0.000 & 0.000 & 0.000 & 0.000 & 0.000 & 0.000 \\
\hline age_clitt2 & & & & & & 1.000 & 0.000 & 0.000 & 0.001 & 0.000 & 0.000 & -0.118 & 0.166 & 0.000 & 0.000 \\
\hline age_clitt3 & & & & & & & 1.000 & 0.000 & 0.000 & 0.000 & 0.000 & 0.000 & 0.000 & 0.000 & 0.000 \\
\hline age_csoill & & & & & & & & 1.000 & -0.005 & 0.000 & 0.000 & 0.000 & 0.000 & 0.000 & 0.000 \\
\hline age_csoil2 & & & & & & & & & 1.000 & -0.011 & -0.021 & -0.004 & 0.005 & 0.000 & 0.000 \\
\hline age_csoil3 & & & & & & & & & & 1.000 & 0.000 & 0.000 & 0.000 & 0.000 & 0.000 \\
\hline fallocc_w & & & & & & & & & & & 1.000 & -0.001 & 0.001 & 0.000 & 0.000 \\
\hline fallocc_l_g & & & & & & & & & & & & 1.000 & -0.742 & 0.000 & 0.000 \\
\hline fallocc_l_w & & & & & & & & & & & & & 1.000 & 0.000 & 0.000 \\
\hline rsratio_w & & & & & & & & & & & & & & 1.000 & 0.000 \\
\hline rsratio_g & & & & & & & & & & & & & & & 1.000 \\
\hline
\end{tabular}

Acknowledgements. We gratefully acknowledge the availability of eddy flux data from: Ray Leuning, Helen Cleugh, Wayne Meyer, Lindsay Hutley, Jason Beringer, Stefan Arndt, Derek Eamus and James Cleverly. Intensive computations were facilitated by Edward King, Matt Paget and Maciej Golebiewski. The manuscript was significantly improved thanks to suggestions from Derek Eamus. This work was supported largely by the Australian Climate Change Science Program. Dr Viscarra Rossel thanks the CSIRO's Sustainable Agriculture Flagship (SAF) Theme 1179 project "National digital mapping of soil organic carbon stocks and composition for improved modelling and assessment".

Edited by: U. Seibt

\section{References}

Arora, V. K. and Boer, G. J.: A GCM-based assessment of the global moisture budget and the role of land-surface moisture reservoirs in processing precipitation, Clim. Dynam., 20, 13-29, 2002.

Ashton, D. H.: The development of even-aged stands of Eucalyptus regnans F. Muell. in Central Victoria, J. Aust. Bot., 24, 397-414, 1976.
Aubinet, M., Grelle, A., Ibrom, A., Rannik, U., Moncrieff, J., Foken, T., Kowalski, A. S., Martin, P. H., Berbigier, P., Bernhofer, C., Clement, R., Elbers, J., Granier, A., Grunwald, T., Morgenstern, K., Pilegaard, K., Rebmann, C., Snijders, W., Valentini, R., and Vesala, T.: Estimates of the annual net carbon and water exchange of forests: The EUROFLUX methodology, Adv. Ecol. Res., 30, 113-175, 2000.

Barrett, D. J.: NPP Multi-Biome: VAST Calibration Data, Oak Ridge National Laboratory Distributed Active Archive Centre, Oak Ridge, TN, 2001.

Barrett, D. J.: Steady state turnover time of carbon in the Australian terrestrial biosphere, Global Biogeochem. Cy., 16, doi:10.1029/2002GB001860, 2002.

Barrett, D. J.: Timescales and Dynamics of Carbon in Australia's Savannas, in: Ecosystem Function in Savannas: Measurement and Modeling at Landscape to Global Scales, edited by: Hill, M. J. and Hanan, N. P., CRC Press, 347-366, 2010.

Beringer, J., Hutley, L. B., Tapper, N. J., and Cernusak, L. A.: Savanna fires and their impact on net ecosystem productivity in North Australia, Glob. Change Biol., 13, 990-1004, 2007.

Beringer, J., Hutley, L. B., Hacker, J. M., Neininger, B., and U, K. T. P.: Patterns and processes of carbon, water and energy cycles 
across northern Australian landscapes: From point to region, Agr. Forest Meteorol., 151, 1409-1416, 2011.

Berry, S. L. and Roderick, M. L.: Changing Australian vegetation from 1788 to 1988: effects of $\mathrm{CO}_{2}$ and land-use change, Aust. J. Bot., 54, 325-338, 2006.

Boening, C., Willis, J. K., Landerer, F. W., Nerem, R. S., and Fasullo, J.: The 2011 La Niña: So strong, the oceans fell, Geophys. Res. Lett., 39, L19602, doi:10.1029/2012GL053055, 2012.

Brutsaert, W.: Derivable formula for long-wave radiation from clear skies, Water Resour. Res., 11, 742-744, 1975.

Canadell, J. G., Le Quere, C., Raupach, M. R., Field, C. B., Buitenhuis, E. T., Ciais, P., Conway, T. J., Gillett, N. P., Houghton, R. A., and Marland, G.: Contributions to accelerating atmospheric $\mathrm{CO}_{2}$ growth from economic activity, carbon intensity, and efficiency of natural sinks, P. Natl. Acad. Sci. USA, 104, 1886618870, 2007.

Cesaraccio, C., Spano, D., Duce, P., and Snyder, R. L.: An improved model for determining degree-day values from daily temperature data. Int. J. Biometeorol., 45, 161-169, 2001.

Chen, X. Y., Hutley, L. B., and Eamus, D.: Carbon balance of a tropical savanna of northern Australia, Oecologia, 137, 405-416, 2003.

Cleugh, H. A., Leuning, R., Mu, Q. Z., and Running, S. W.: Regional evaporation estimates from flux tower and MODIS satellite data, Remote Sens. Environ., 106, 285-304, 2007.

DCCEE: Australia's national greenhouse accounts: quarterly update of Australia's National Greenhouse Gas Inventory (December Quarter 2011), Department of Climate Change and Energy Efficiency, Australian Government, Canberra, 2012.

Dean, C., Roxburgh, S., and Mackey, B. G.: Growth modelling of Eucalyptus regnans for carbon accounting at the landscape scale, in: edited by: Amaro, A., Reed, D., and Soares, P., Modelling Forest Systems, CABI Publishing, Wallingford, UK, 2003.

DeLucia, E. H., Drake, J. E., Thomas, R. B., and Gonzalez-Meler, M.: Forest carbon use efficiency: is respiration a constant fraction of gross primary production?, Glob. Change Biol., 13, 11571167, 2007.

Doherty, J.: PEST, Watermark numerical Computing, Townesville, 2004.

Donohue, R. J., McVicar, T. R., and Roderick, M. L. Climate-related trends in Australian vegetation cover as inferred from satellite observations, 1981-2006, Glob. Change Biol., 15, 1025-1039, 2009.

Eamus, D., Myers, B., Duff, G., and Williams, R. A cost-benefit analysis of leaves of eight Australian savanna tree species of differing leaf life-span, Photosynthetica, 36, 575-586, 1999.

Eamus, D., Chen, X., Kelley, G., and Hutley, L. B.: Root biomass and root fractal analyses of an open Eucalyptus forest in a savanna of north Australia, Aust. J. Bot., 50, 31-41, 2002.

Farquhar, G. D., Caemmerer, S. V., and Berry, J. A.: A biochemicalmodel of photosynthetic $\mathrm{CO}_{2}$ assimilation in leaves of $\mathrm{C}-3$ species, Planta, 149, 78-90, 1980.

Fuchs, M., Campbell, G. S., and Papendick, R. I.: Analysis of sensible and latent heat-flow in a partially frozen unsaturated soil, Soil Sci. Soc. Am. J., 42, 379-385, 1978.

Gifford, R. M.: Plant respiration in productivity models: conceptualisation, representation and issues for global terrestrial carboncycle research, Funct. Plant Biol., 30, 171-186, 2003.
Grant, I., Jones, D., Wang, W., Fawcett, R., and Barratt, D.: Meteorological and remotely sensed datasets for hydrological modelling: A contribution to the Australian Water Availability Project, Catchment-scale Hydrological Modelling \& Data Assimilation (CAHMDA-3) International Workshop on Hydrological Prediction: Modelling, Observation and Data Assimilation, Melbourne, 2008.

Grierson, P. F., Adams, M. A., and Attiwill, P. M.: Estimates of carbon storage in the aboveground biomass of victorias forests, Aust. J. Bot., 40, 631-640, 1992.

Hattersley, P. W.: The distribution of C3-grass and C4-grasses in Australia in relation to climate, Oecologia, 57, 113-128, 1983.

Haverd, V. and Cuntz, M.: Soil-Litter-Iso A one-dimensional model for coupled transport of heat, water and stable isotopes in soil with a litter layer and root extraction, J. Hydrol., 388, 438-455, 2010.

Haverd, V., Cuntz, M., Griffith, D., Keitel, C., Tadros, C., and Twining, J.: Measured deuterium in water vapour concentration does not improve the constraint on the partitioning of evapotranspiration in a tall forest canopy, as estimated using a soil vegetation atmosphere transfer model, Agr. Forest Meteorol., 151, 645-654, 2011.

Haverd, V., Raupach, M. R., Briggs, P. R., J. G. Canadell., Davis, S. J., Law, R. M., Meyer, C. P., Peters, G. P., Pickett-Heaps, C., and Sherman, B.: The Australian terrestrial carbon budget, Biogeosciences, 10, 851-869, doi:10.5194/bg-10-851-2013, 2013.

Houldcroft, C. J., Grey, W. M. F., Barnsley, M., Taylor, C. M., Los, S. O., and North, P. R. J.: New Vegetation Albedo Parameters and Global Fields of Soil Background Albedo Derived from MODIS for Use in a Climate Model, J. Hydrometeorol., 10, 183-198, 2009.

Hutchinson, M. F., Nix, H. A., and McMahon, J. P.: Climate constraints on cropping systems, in: edited by: Pearson, C. J., Field Crop Systems, Elsevier, Amsterdam, 37-58, 1992.

Hutchinson, M. F., McIntyre, S., Hobbs, R. J., Stein, J. L., Garnett, S., and Kinloch, J.: Integrating a global agro-climatic classification with bioregional boundaries in Australia, Global Ecolo. Biogeogr., 14, 197-212, 2005.

Hutley, L. B., O'Grady, A. P., and Eamus, D.: Evapotranspiration from eucalypt open-forest savanna of northern Australia, Funct. Ecol., 14, 183-194, 2000.

Jobbagy, E. G. and Jackson, R. B.: The vertical distribution of soil organic carbon and its relation to climate and vegetation, Ecol. Appl., 10, 423-436, 2000.

Jones, D. A., Wang, W., and Fawcett, R.: High-quality spatial climate data-sets for Australia, Aust. Meteorol. Oceanogr. J., 58, 233-248, 2009.

Kattge, J., Knorr, W., Raddatz, T., and Wirth, C.: Quantifying photosynthetic capacity and its relationship to leaf nitrogen content for global-scale terrestrial biosphere models, Glob. Change Biol., 15, 976-991, 2009.

Keeling, C. D., Piper, S. C., Bacastow, R. B., Wahlen, M., Whorf, T. P., Heimann, M., and Meijer, H. A.: Exchanges of atmospheric $\mathrm{CO}_{2}$ and $13 \mathrm{CO}_{2}$ with the terrestrial biosphere and oceans from 1978 to 2000, I. Global aspects, Scripps Institution of Oceanography, San Diego, 2001.

Keith, H., van Gorsel, E., Jacobsen, K. L., and Cleugh, H. A.: Dynamics of carbon exchange in a Eucalyptus forest in response to interacting disturbance factors, Agr. Forest Meteorol., 153, 67- 
81, 2012.

King, E. A., Paget, M. J., Briggs, P. R., Trudinger, C. M., and Raupach, M. R.: Operational Delivery of Hydro-Meteorological Monitoring and Modeling Over the Australian Continent, IEEE J. Sel. Top. Appl., 2, 241-249, 2009.

King, E. A., Van Niel, T. G., Van Dijk, A. I., Wang, Z., Paget, M. J., Raupach, T., Bastianssen, W. G., Guerschman, J., Haverd, V., McVicar, T. R., Miltenburg, I., Raupach, M. R., Renzullo, L. J., and Zhang, Y.: Actual Evapotranspiration Estimates for Australia: inter-comparison and evaluation, CSIRO, Canberra, 2011.

Köppen, W.: Die Klimate der Erde, Walter de Gruyter, Berlin, 1369, 1923.

Kowalczyk, E. A., Wang, Y. P., and Law, R. M.: The CSIRO Atmospheric Biosphere Land Exchange (CABLE) model for use in climate models and as an offline model, Pap. 013, CSIRO Mar. and Atmos. Res., Aspendale, Vic., Australia, 2006.

Lai, C. T. and Katul, G.: The dynamic role of root-water uptake in couplinhg potential to actual transpiration, Adv. Water Resour., 23, 427-439, 2000.

Lawrence, D. M., Thornton, P. E., Oleson, K. W., and Bonan, G. B.: The partitioning of evapotranspiration into transpiration, soil evaporation, and canopy evaporation in a GCM: Impacts on landatmosphere interaction, J. Hydrometeorol., 8, 862-880, 2007.

Leuning, R., Kelliher, F. M., Depury, D. G. G., and Schulze, E. D.: Leaf nitrogen, photosynthesis, conductance and transpiration scaling from leaves to canopies, Plant Cell Environ., 18, 11831200, 1995.

Leuning, R., Cleugh, H. A., Zegelin, S. J., and Hughes, D.: Carbon and water fluxes over a temperate Eucalyptus forest and a tropical wet/dry savanna in Australia: measurements and comparison with MODIS remote sensing estimates, Agr. Forest Meteorol., 129, 151-173, 2005.

Leuning, R., van Gorsel, E., Massman, W. J., and Isaac, P. R.: Reflections on the surface energy imbalance problem, Agr. Forest Meteorol., 156, 65-74, 2012.

Lu, H., Raupach, M. R., McVicar, T. R., and Barrett, D. J.: Decomposition of vegetation cover into woody and herbaceous components using AVHRR NDVI time series, Remote Sens. Environ., 86, 1-18, 2003.

Martin, D., Beringer, J., Hutley, L. B., and McHugh, I.: Carbon cycling in a mountain ash forest: Analysis of below ground respiration, Agr. Forest Meteorol., 147, 58-70, 2007.

McKenzie, N. J. and Hook, J.: Interpretation of the Atlas of Australian Soils. Technical Report, 94/1992, CSIRO Division of Soils, Canberra, 1992.

McKenzie, N. J., Jacquier, D. W., Ashton, L. J., and Creswell, H. P.: Estimation of soil properties using the Atlas of Australian Soils, Canberra, 2000.

Medlyn, B. E., Dreyer, E., Ellsworth, D., Forstreuter, M., Harley, P. C., Kirschbaum, M. U. F., Le Roux, X., Montpied, P., Strassemeyer, J., Walcroft, A., Wang, K., and Loustau, D.: Temperature response of parameters of a biochemically based model of photosynthesis. II. A review of experimental data, Plant Cell Environ., 25, 1167-1179, 2002.

Mitchell, P. J., Veneklaas, E., Lambers, H., and Burgess, S. S. O.: Partitioning of evapotranspiration in a semi-arid eucalypt woodland in south-western Australia, Agr. Forest Meteorol., 149, 25$37,2009$.
Mokany, K., Raison, R. J., and Prokushkin, A. S.: Critical analysis of root: shoot ratios in terrestrial biomes, Glob. Change Biol., 12, 84-96, 2006.

Murphy, B. P. and Bowman, D.: Seasonal water availability predicts the relative abundance of C-3 and C-4 grasses in Australia, Glob. Ecol. Biogeogr., 16, 160-169, 2007.

Northcote, K. H., Beckmann, G. G., Bettenay, E., Churchward, H. M., Van Dijk, D. C., Dimmock, G. M., Hubble, G. D., Isbell, R. F., McArthur, W. M., Murtha, G. G., Nicolls, K. D., Paton, T. R., Thompson, C. H., Webb, A. A., and Wright, M. J.: Atlas of Australian Soils, Sheets 1 to 10, With explanatory data, CSIRO Australia and Melbourne University Press, Melbourne, 1960.

Northcote, K. H., Hubble, G. D., Isbell, R. F., Thompson, C. H., and Bettenay, E.: A Description of Australian Soils, CSIRO Australia, 1-170, 1975.

Paltridge, G. W. and Platt, C. M. R.: Radiative processes in meteorology and climatology Elsevier Scientific Pub. Co, Amsterdam, New York, 1976.

Pan, Y. D., Birdsey, R. A., Fang, J. Y., Houghton, R., Kauppi, P. E., Kurz, W. A., Phillips, O. L., Shvidenko, A., Lewis, S. L., Canadell, J. G., Ciais, P., Jackson, R. B., Pacala, S. W., McGuire, A. D., Piao, S. L., Rautiainen, A., Sitch, S., and Hayes, D.: A Large and Persistent Carbon Sink in the World's Forests, Science, 333, 988-993, 2011.

Polglase, P. J., Adams, M. A., and Attiwill, P. M.: Measurement and Modelling of carbon Storage in a Chronosequence of Mountain Ash Forests: implications for regional and Global carbon Budgets, State Electricity Commission of Victoria, Melbourne, 1994.

Raison, J., Keith, H., Barrett, D. J., Burrows, B., and Grierson, P.: Spatial Estimates of Biomass in "Mature" Native Vegetation, Australian Greenhouse Office, 2003.

Raupach, M. R., Finkele, K., and Zhang, L.: SCAM (Soil-Canopy Atmosphere Model): Description and comparison with field data, CSIRO Centre for Environmental Mechanics, Canberra, ACT, Australia, 1997.

Raupach, M. R., Kirby, J. M., Barrett, D. J., and Briggs, P. R.: Balances of Water, Carbon, Nitrogen and Phosphorus in Australian Landscapes: (1) Project Description and Results, CSIRO Land and Water, 2001.

Raupach, M. R., Rayner, P. J., Barrett, D. J., DeFries, R. S., Heimann, M., Ojima, D. S., Quegan, S., and Schmullius, C. C.: Model-data synthesis in terrestrial carbon observation: methods, data requirements and data uncertainty specifications, Glob. Change Biol., 11, 378-397, 2005.

Raupach., M. R. R., Briggs, P. R., Haverd, V., King, E. A., Paget, M., and Trudinger, C. M.: Australian Water Availability Project (AWAP): CSIRO Marine and Atmospheric Research Component: Final Report for Phase 3, Canberra, 2009.

Roxburgh, S. H.: Description and implementation of a model for simulating carbon dynamics and land clearing impacts for the Injune case study, CRC for Greenhouse Accounting, 2005.

Roxburgh, S. H., Barrett, D. J., Berry, S. L., Carter, J. O., Davies, I. D., Gifford, R. M., Kirschbaum, M. U. F., McBeth, B. P., Noble, I. R., Parton, W. G., Raupach, M. R. and Roderick, M. L.: A critical overview of model estimates of net primary productivity for the Australian continent, Funct. Plant Biol., 31, 1043-1059, 2004.

Roxburgh, S. H., Mackey, B. G., Dean, C., Randall, L., Lee, A., and Austin, J.: Organic carbon partitioning in soil and litter in 
subtropical woodlands and open forests: a case study from the Brigalow Belt, Queensland, Rangeland J., 28, 115-125, 2006 a.

Roxburgh, S. H., Wood, S. W., Mackey, B. G., Woldendorp, G., and Gibbons, P.: Assessing the carbon sequestration potential of managed forests: a case study from temperate Australia, J. Appl. Ecol., 43, 1149-1159, 2006b.

Sakaguchi, K. and Zeng, X. B.: Effects of soil wetness, plant litter, and under-canopy atmospheric stability on ground evaporation in the Community Land Model (CLM3.5), J. Geophys. Res.Atmos., 114, D01107, doi:10.1029/2008JD010834, 2009.

Saugier, B., Roy, J., and Mooney, H. A.: Estimations of global terrestrial productivity: Converging towards a single number?, in: Terrestrial Global Productivity, edited by: Roy, J., Saugier, B., and Mooney, H. A., Academic Press, San Diego, 2001.

Scurlock, J. M. O., Johnson, K., and Olson, R. J.: Estimating net primary productivity from grassland biomass dynamics measurements, Glob. Change Biol., 8, 736-753, 2002.

Sitch, S. A. and Friedlingstein, P.: GCP-Land trends: modelling protocol, University of Exeter, available at: http://dgvm.ceh.ac. uk/system/files/Trendyprotocol20Nov20110.pdf (last access: 25 January 2013), 2011.

Swinbank, W. C.: Long-wave radiation from clear skies, Q. J. Roy. Meteorol. Soc., 89, 339-348, 1963.

Thompson, M. V. and Randerson, J. T.: Impulse response functions of terrestrial carbon cycle models: method and application, Glob. Change Biol., 5, 371-394, 1999.

Thornley, J. H. M.: Plant growth and respiration re-visited: maintenance respiration defined - it is an emergent property of, not a separate process within, the system - and why the respiration: photosynthesis ratio is conservative, Ann. Bot.-London, 108, 1365-1380, 2011.

Van Gorsel, E., Leuning, R., Cleugh, H. A., Keith, H., and Suni, T.: Nocturnal carbon efflux: reconciliation of eddy covariance and chamber measurements using an alternative to the $\mathrm{u}\left({ }^{*}\right)$-threshold filtering technique, Tellus B, 59, 397-403, 2007. van Gorsel, E., Leuning, R., Cleugh, H. A., Keith, H., Kirschbaum, M. U. F., and Suni, T.: Application of an alternative method to derive reliable estimates of nighttime respiration from eddy covariance measurements in moderately complex topography, Agr. Forest Meteorol., 148, 1174-1180, 2008.

van Gorsel, E., Delpierre, N., Leuning, R., Black, A., Munger, J. W., Wofsy, S., Aubinet, M., Feigenwinter, C., Beringer, J., Bonal, D., Chen, B. Z., Chen, J. Q., Clement, R., Davis, K. J., Desai, A. R., Dragoni, D., Etzold, S., Grunwald, T., Gu, L. H., Heinesch, B., Hutyra, L. R., Jans, W. W. P., Kutsch, W., Law, B. E., Leclerc, M. Y., Mammarella, I., Montagnani, L., Noormets, A., Rebmann, C., and Wharton, S.: Estimating nocturnal ecosystem respiration from the vertical turbulent flux and change in storage of $\mathrm{CO}_{2}$, Agr. Forest Meteorol., 149, 1919-1930, 2009.

Vaze, J., Chiew, F. H. S., Perraud, J. M., Viney, N., Post, D., Teng, J., Wang, B., Lerat, J., and Goswami, M.: Rainfall-runoff modelling across southeast Australia: Datasets, models and results, Aust. J. Water Resour., 14, 101-113, 2011.

Wang, Y. P. and Barrett, D. J.: Estimating regional terrestrial carbon fluxes for the Australian continent using a multiple-constraint approach I. Using remotely sensed data and ecological observations of net primary production, Tellus B, 55, 270-289, 2003.

Wang, Y. P., Law, R. M., and Pak, B.: A global model of carbon, nitrogen and phosphorus cycles for the terrestrial biosphere, Biogeosciences, 7, 2261-2282, doi:10.5194/bg-7-2261-2010, 2010.

Wang, Y. P., Kowalczyk, E., Leuning, R., Abramowitz, G., Raupach, M. R., Pak, B., van Gorsel, E., and Luhar, A.: Diagnosing errors in a land surface model (CABLE) in the time and frequency domains, J. Geophys. Res.-Biogeo., 116, G01034, doi:10.1029/2010jg001385, 2011.

Whitley, R. J., Macinnis-Ng, C. M. O., Hutley, L. B., Beringer, J., Zeppel, M., Williams, M., Taylor, D., and Eamus, D.: Is productivity of mesic savannas light limited or water limited? Results of a simulation study, Glob. Change Biol., 17, 3130-3149, 2011.

Zhang, Y. Q., Viney, N., Chen, Y., and Li, H. Y.: Collation of streamflow dataset for 719 unregulated Australian catchments, CSIRO: Water for a Healthy Country National Research Flagship, 2011. 